Review

\title{
Tool Wear and Life Span Variations in Cold Forming Operations and Their Implications in Microforming
}

\author{
Anders E. W. Jarfors ${ }^{1, *}$, Sylvie J. Castagne ${ }^{2}$, Atsushi Danno ${ }^{3}$ and Xinping Zhang ${ }^{4}$ \\ 1 School of Engineering, Jönköping University, Jönköping 55111, Sweden \\ 2 School of Mechanical and Aerospace Engineering, Nanyang Technological University, Singapore 639798, \\ Singapore; SCastagne@ntu.edu.sg \\ 3 Singapore Institute of Manufacturing Technology, Singapore 637772, Singapore; \\ danno@SIMTech.a-star.edu.sg \\ 4 School of Materials Science and Engineering, Nanjing University of Science and Technology, Nanjing 210094, \\ China; zxp_0517@163.com \\ * Correspondence: anders.jarfors@ju.se; Tel.: +46-036-101-651
}

Academic Editor: Manoj Gupta

Received: 4 November 2016; Accepted: 21 December 2016; Published: 27 December 2016

\begin{abstract}
The current paper aims to review tooling life span, failure modes and models in cold microforming processes. As there is nearly no information available on tool-life for microforming the starting point was conventional cold forming. In cold forming common failures are (1) over stressing of the tool; (2) abrasive wear; (3) galling or adhesive wear, and (4) fatigue failure. The large variation in tool life observed in production and how to predict this was reviewed as this is important to the viability of microforming based on that the tooling cost takes a higher portion of the part cost. Anisotropic properties of the tool materials affect tool life span and depend on both the as-received and in-service conditions. It was concluded that preconditioning of the tool surface, and coating are important to control wear and fatigue. Properly managed, the detrimental effects from surface particles can be reduced. Under high stress low-cycle fatigue conditions, fatigue failure form internal microstructures and inclusions are common. To improve abrasive wear resistance larger carbides are commonly the solution which will have a negative impact on tooling life as these tend to be the root cause of fatigue failures. This has significant impact on cold microforming.
\end{abstract}

Keywords: fatigue; wear; life-span; modeling; prediction; tool material; microforming

\section{Introduction}

In cold forging the common failures are (1) over stressing the tool; (2) abrasive wear failure leading to flawed tolerances of the workpiece and poor surfaces; (3) galling leading to poor surface of the workpiece and material buildup and wear of the tool, and (4) fatigue failure. Miniaturization of components and the requirements for tighter tolerances lead to increasing contact pressures at the tool-workpiece interfaces in cold forming operations. Consequently, fatigue and wear of forming tools also increase.

Currently overstressing in tooling can be estimated and reasonably well predicted using finite element modelling (FEM) including elastic defoemation with deviation of product shape [1], but life-span prediction for fatigue and wear with high tool hardness, as required in microforming, is a relatively new area needing further study [2-4].

The scope of current paper is not on the conditions that will result in product shape deviation but of the wear and fatigue failure of tooling used for cold forming operations with particular focus on microforming. The lack of work on tool life in microforming made it necessary to start with a review of tooling lifespan and tooling failure in conventional cold forging processes, models that can account 
for the stochastic behavior of wear and fatigue phenomena will be discussed. An in-depth review of the material properties of typical tool steels will then be presented in relation to their microstructures and their effects on fatigue life and wear behavior. The paper will follow with a presentation of the characteristics and fatigue behavior of coatings typically used on tooling before discussing the implications of changes to surfaces in service. Finally, the implications of the tribological and friction size effects on the tooling surfaces at the microforming scale will be discussed.

\section{Tool-Life Variations and Methods to Predict Tool-Life}

\subsection{Observed Tooling Life Span Variation and Failure}

Meidert and Hansel [5] studied the tool lifespan for typical net shape cold forging parts produced for the automotive industry (see Figure 1a). It should here be noted that the failure mode in this study was primarily fatigue failure or over load and rarely wear failure. The life span observed ranges from a few hundred up to 90,000 strokes. Some cases of short tool life can most likely be associated with wrong setup and common factory type mistakes, but this would still render a lifetime variation close to a factor eight to explain. This variation must be better understood in order to make microforming a viable process.

Tabe [6] illustrated qualitatively the causes of tool failure as a function of tool hardness as shown in Figure 1b. It is suggested based on this figure that maximum tool life is not given by maximum hardness but that there is an optimum hardness. It is, however, important to bear in mind that as formed parts are getting smaller and more complicated, the necessary local pressures increase necessitating harder tools. In this context, failure by fatigue will be increasingly important to manage. Fatigue failure has a strong stochastic nature which will be discussed more in detail below.

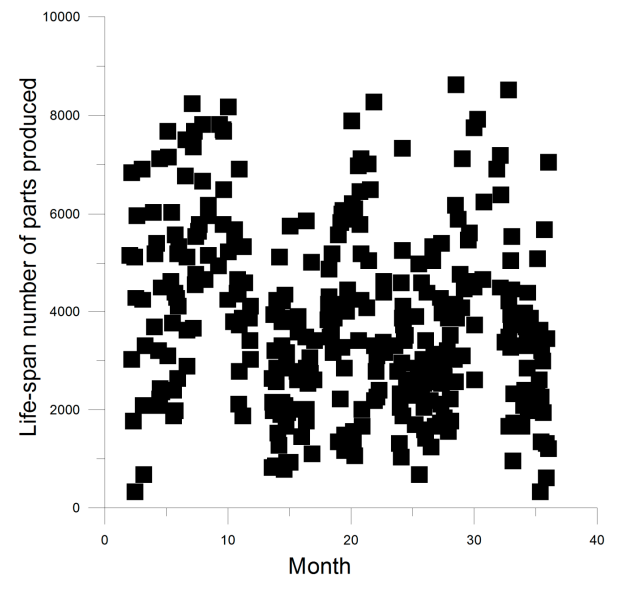

(a)

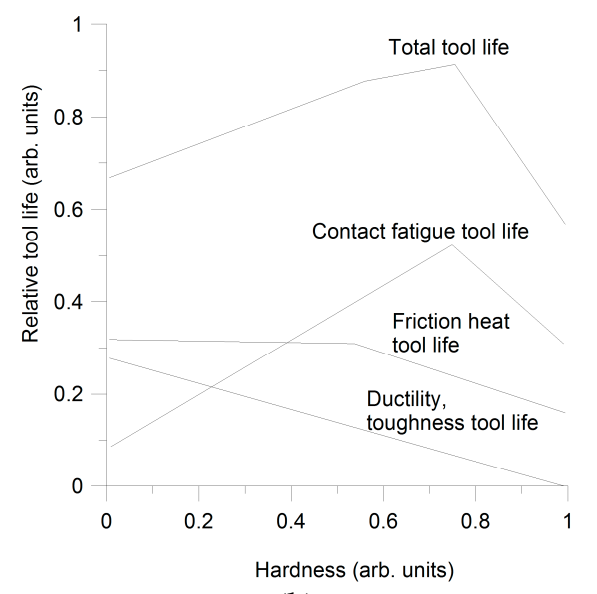

(b)

Figure 1. Tool life, (a) data of life spans of individual tool inserts over time illustrating the large variation observed under industrial practice conditions, after ref. [5]; (b) schematic relation between toll hardness and reasons for failure in tooling after ref. [6].

Broeckmann [7,8] studied the microstructure of tool steel and its resulting properties. Broeckmann [7] concluded that as the tool material was made harder the influence of the rolling or forging process was becoming greater showing up directional properties in the transverse and longitudinal directions, as shown in Figure 2. This was due to the elongation of the microstructural features. As the tool material is being cut at the tool manufacturer the original orientation is not always kept under full control making this an inherent source for variation of the fatigue life. The same type of variation between transverse and longitudinal directions was observed for toughness, which influences fatigue crack growth rate, for AISI 01, D2, D3 ASP 2023 and Vanadis10 [9]. Modeling attempts to address the relation between phase arrangements and toughness have also been presented [10]. It was suggested 
that local variations in carbide concentration in tool steel should result in a layered structure causing stress concentrations in the material between layer of high carbide concentration and low carbide concentration and not just around the particles themselves [11]. This strongly suggests that for hard tool, the tool cavity orientation relative to rolling and forging direction becomes important. In microforming tool pressures are high with significant stress concentration at sharp features. The ability to model tool life thus becomes increasingly critical, as tool cost is a decisive factor. A correct relation between applied stress and material anisotropy is thus also becoming more and more important.

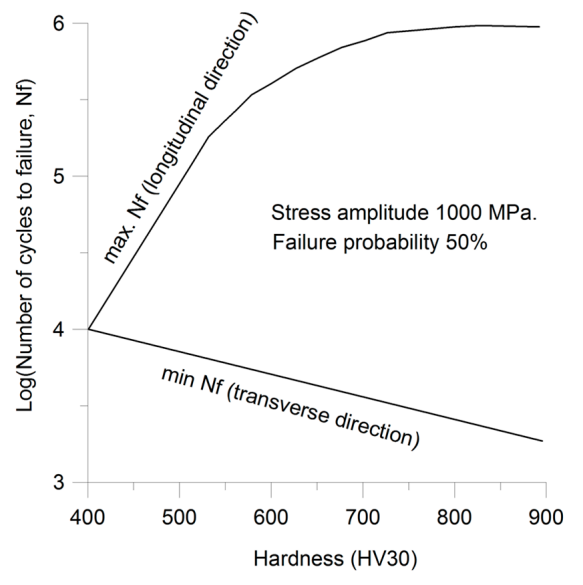

Figure 2. Material anisotropy effects in fatigue-life for tool steels after ref. [7].

Lange and coworkers [3] studied cold forward extrusion and identified for this type of die that the failure modes were predominantly of three different kinds, namely overloading, fatigue failure and wear, as illustrated in Figure 3. They concluded that reducing the stress level in cold-forging tooling by modifications in the design has the greatest influence on tool life. Reducing the influence of radial machining and polishing marks through jet-honing and shot-peening has also some positive effect on die life whereas increasing the overall hardness of the insert reduces the toughness of the tool material and, thus, accelerates crack growth. However, increasing the hardness of the surface by CVD coating can have a positive effect on die-life.

In order to be able to reduce stress at critical points in the die and to ensure that the material response is appropriate it is thus necessary to address the following points [3]:

- Accurately analyze and measure the tool material properties

- This involves understanding of the influence of the carbides and inclusions and their type, size and size distribution as well as clustering effects to evaluate their effects on:

- $\quad$ Fatigue crack initiation and growth

- Wear rates

- Accurately understand the influence of the surface conditions in the tooling

- Influence of the residual and overlay stresses in the tool surface

- Influence of surface finishing

- Influence of the type of coating and coating properties

- Understand how to characterize properties

- Capability to characterize the base material to be able to describe the nature and origin of the tool material property variation

- Capability to characterize the surface coating properties 


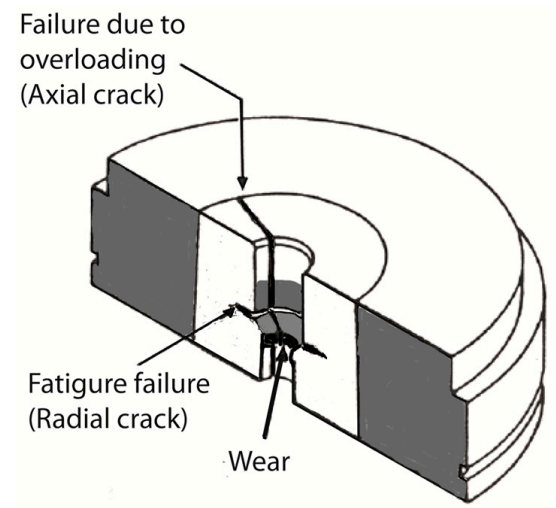

Figure 3. Typical locations of failures and their location in a die after ref. [3].

\subsection{Principal Schemes for Simulation and Prediction of Tool Life}

One of the major damages that limit the die life in cold forging is low-cycle fatigue. The various methods for material testing, modeling and finite element (FE) simulations to analyse the effects of different modifications in the process and tool design on die life optimization through FE simulation were summarized by GroenBaek and Hensel [4].

\subsubsection{Fatigue Life Modeling}

Strategies developed to tackle tool-life naturally depend on the nature of failure in the tools. For high volume cold forged parts with net shaped complex surfaces, fatigue cracking of the active tool elements is the leading cause of failure. The most efficient route to do this analysis is to use FEM to assess [2]:

- Tool load (contact stress distribution at the die-workpiece interface).

- FE based elastic-plastic stress-strain analysis (stress-strain curve required).

- A minimum of two loading cycles to determine the cyclic response of the tooling at the highest loaded zone.

Knoerr et al. [2] developed the analysis flow chart shown in Figure 4. They used a local strain approach for damage analysis (strain life data for active tool component required) and coupled this to data for strain amplitude and cycles to crack initiation (see Figure 5).

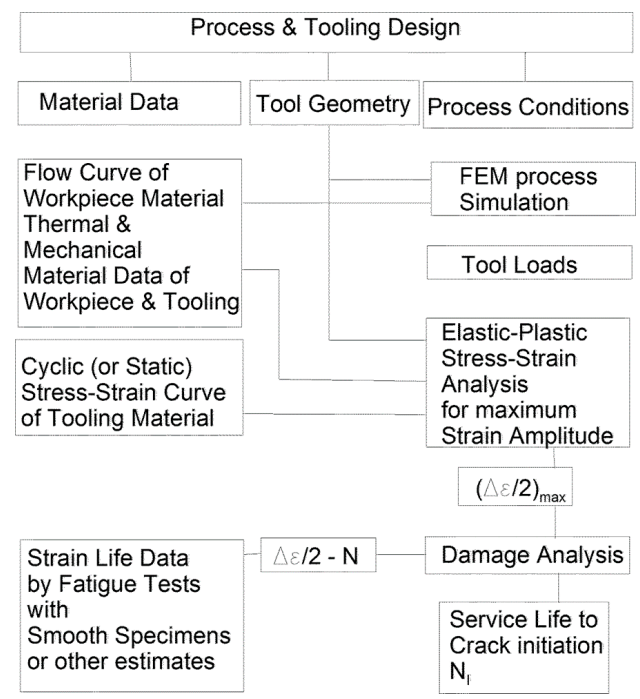

Figure 4. A suggested flow chart for the assessment of fatigue life of tools after ref. [1]. 
In Figure 5 it is clear that a reasonable first estimate of the tool life is possible by the local strain approach using the total strain amplitude approach. The analysis does however not reproduce nor predicts the experimental variations. Alternative approaches are thus necessary to reach quantification of the variations in die life.

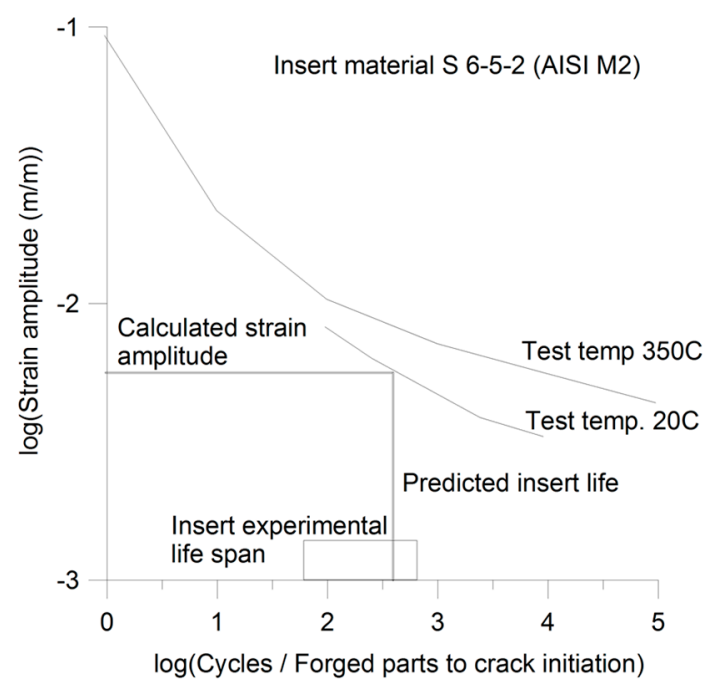

Figure 5. Illustration of the outcome of a local strain approach for damage analysis ref. [2].

The nature of the data required depends greatly on the damage considered. Falk et al. [12] assessed the applicability of different damage models to the case of closed die forging with the critical, process-dependent load is quantified and localized by using a FEM.

The simplest approach is the Wöhler approach or usage of the SN curve where the tooling life span, $N_{f}$, is

$$
N_{f}=N_{D}\left(\frac{\sigma_{a}}{\sigma_{D}}\right)^{k}
$$

where $\sigma_{a}$ is the stress amplitude. This model can be applied when the values for fatigue limit $\sigma_{D}$, its corresponding lifetime $N_{D}$ and the constant $k$ are known. The drawback is that the required values are only available for specific relations between the maximum and minimum stress [12].

The next approach is the local strain approach with the total strain $\varepsilon_{a, t o t}$ as measure and $\varepsilon_{a, e l}, \varepsilon_{a, p l}$ as the elastic and plastic strain components, respectively. The influence of the mean stress $\sigma_{m}$ is taken into consideration by the modification of the elastic component as in Equation (3)

$$
\begin{gathered}
\varepsilon_{a, t o t}=\varepsilon_{a, e l}+\varepsilon_{a, p l} \\
\varepsilon_{a, t o t}=\frac{\sigma_{f}^{\prime}-\sigma_{m}}{E}\left(2 N_{f}\right)^{b}+\varepsilon_{f}^{\prime}\left(2 N_{f}\right)^{c}
\end{gathered}
$$

where $\sigma_{f}^{\prime}$ is the fatigue strength and $\sigma_{m}$ is the mean stress, $E$ is the Young's modulus, $\varepsilon_{f}^{\prime}$ is the strain level in the fatigue cycle and $b$ and $c$ are constants. The effect of multi-axial stress conditions can be correlated with uni-axial fatigue data under the assumption that all stress components oscillate synchronous with proportional mean values amplitudes. This results in a more flexible approach which was also chosen by e Knoerr et al. [2].

A more generic approach is the local energy approach [12]. The local energy approach can take the work performed at the surface and $\Delta W^{e++}$ multi-axial stress conditions into account. The total work, can be expressed as

$$
\Delta W^{e++}=\frac{1}{2}\left(\frac{\Delta \sigma}{2}+\Delta \sigma_{m}\right)\left(\frac{\Delta \varepsilon}{2}+\varepsilon_{m}\right)
$$


where $\Delta \sigma_{m}, \varepsilon_{m}$ is the mean stress and strain respectively and $\Delta \sigma, \Delta \varepsilon$ is the stress and strain amplitudes, respectively. The effective work of damage, $\Delta W^{e f f}$, is then expressed as

$$
\Delta W^{e f f}=\Delta W^{e++}-\Delta W^{h}
$$

The hydrostatic component $\Delta W^{h}$ can be expressed as

$$
\Delta W^{h}=\frac{3}{8} \Delta \sigma_{h} \Delta \varepsilon_{h}
$$

The life span of the tool can in this context be expressed as

$$
N_{f}=\frac{1}{2}\left(\frac{2 E \Delta W^{e f f}}{\sigma_{f}^{\prime 2}}\right)^{1 / 2 b}
$$

Falk et al. [12] concluded that the local energy approach in the study yielded the most satisfactory results as a prediction tool even though other techniques have lately successfully been used for engineering solutions of die life extension [13-15].

\subsubsection{Wear Life Modeling}

Lee et al. [16] studied a bolt forming operation and included strain hardening in their model. Tool wear and fatigue is not uniquely determined by the tool and the process set-up but there is a strong component of the workpiece properties in the balance between the wear failure and the fatigue failure. As fatigue model they chose the simplest model, the Wöhler type of model, and included workpiece strain hardening expressed as

$$
N_{f}=0.5\left(\frac{2.5 K+K n-1482.8}{\sigma_{f}^{\prime}+499.3-2.3 K-0.9 K n}\right)^{1 / b}
$$

Here $N_{f}$ is the fatigue life of the tool, $K$ is the strength coefficient of the work piece, $n$ is the strain hardening coefficient of the work piece, $\sigma_{f}^{\prime}$ is the fatigue strength coefficient for the tool material $(33,415 \mathrm{MPa})$ and $b$ is the fatigue strength exponent $(-0.289)$ for the tool material [16]. The work-piece properties are collated in Table 1.

Table 1. Tool life calculated from integrated model for fatigue life, $N_{\mathrm{f}}$, wear life $N_{\mathrm{W}}$, using strength coefficient, $K$ and strain hardening exponent $n$ [16].

\begin{tabular}{cccccccc}
\hline Materials & $\boldsymbol{K} \mathbf{( M P a )}$ & $\boldsymbol{n}$ & $\boldsymbol{D}_{\mathbf{A}} \mathbf{( n m )}$ & $\boldsymbol{D}_{\mathbf{B}} \mathbf{( n m )}$ & $\boldsymbol{N}_{\mathbf{W}}\left(\mathbf{1 0}^{\mathbf{3}}\right)$ & $\boldsymbol{N}_{\mathbf{f}}\left(\mathbf{1 0}^{\mathbf{3}}\right)$ & Tool Life $\left(\mathbf{1 0}^{\mathbf{3}}\right)$ \\
\hline AISI4135 & 900 & 0.084 & 0.754 & 0.957 & 418 & 133 & 133 \\
AISI1045 & 896 & 0.109 & 1.060 & 0.749 & 377 & 102 & 102 \\
AISI51B20 & 813 & 0.129 & 1.470 & 0.625 & 272 & 321 & 272 \\
AISI10B22 & 779 & 0.104 & 0.799 & 0.666 & 500 & 557 & 500 \\
\hline
\end{tabular}

To model the wear they chose the commonly used Archard's model where the incremental volume worn off, $d V$ is expressed as

$$
d V=k \frac{d P d L}{H}
$$

Here $k$ is an experimental wear coefficient influenced by variation in wear conditions (temperature, environment, i.e., presence of chlorine amount of debris and so forth), $P$ is pressure and $H$ is hardness of the worn part. For the current planar sliding geometry, it is possible to rewrite this as

$$
d V=d Z d A
$$




$$
\begin{gathered}
d P=\sigma_{n} d A \\
d L=u d t
\end{gathered}
$$

where $Z$ is height, $A$ is area, $\sigma_{n}$ is normal pressure at the surface, $u$ is sliding speed and $t$ is time, resulting in that

$$
d Z=k \frac{\sigma_{n} u d t}{H}
$$

The height change resulting from wear, $Z$, of the bolt forming tool then becomes

$$
Z(r, t)=\frac{k}{H} \int_{0}^{t} \sigma_{n}(r, t) u(r, t) d t
$$

The outcome from the simulations was subjected to regression analysis of the total wear depth $D$, for two critical areas, $A$ and $B$ located at the bottom and top of the die. For these two locations, wear depth can be expressed as function of the work piece properties as

$$
\mathrm{D}_{\mathrm{A}}=\mathrm{K}\left(1.30 \times 10^{-5}-4.14 \times 10^{-4} n+0.00478 n^{2}-0.0232 n^{3}+0.0403^{4}\right)
$$

and

$$
\mathrm{D}_{\mathrm{B}}=\mathrm{K}\left(50.35 \exp \left(-\frac{\mathrm{n}}{0.0040}\right)+3.49 \times 10^{-7} \exp \left(-\frac{n}{0.17}\right)+6.73 \times 10^{-8}\right)
$$

These depths are being worn for each blow and it was assumed that the wear rate did not change. The wear tolerance was set to $0.4 \mathrm{~mm}$. The correlation between work-piece properties and tool life are shown in Figure 6a,b.

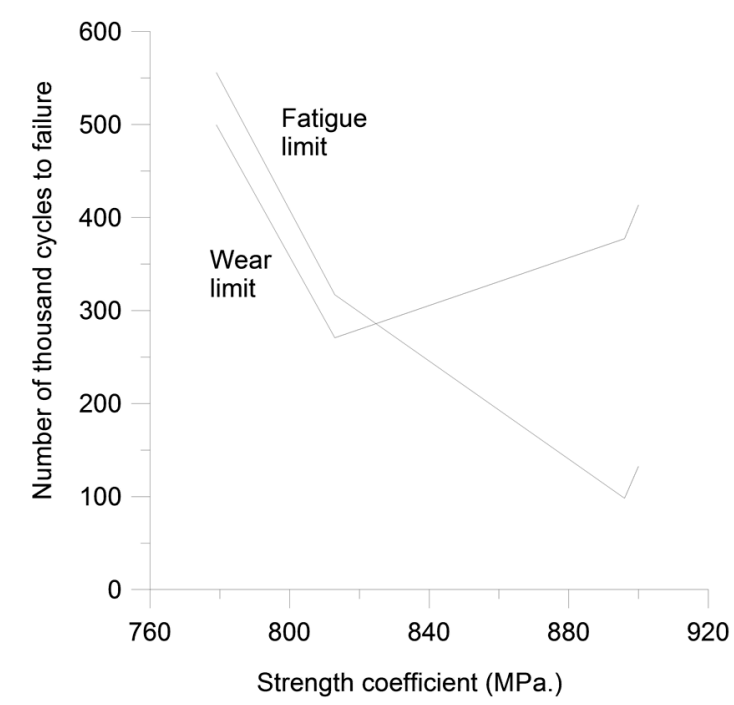

(a)

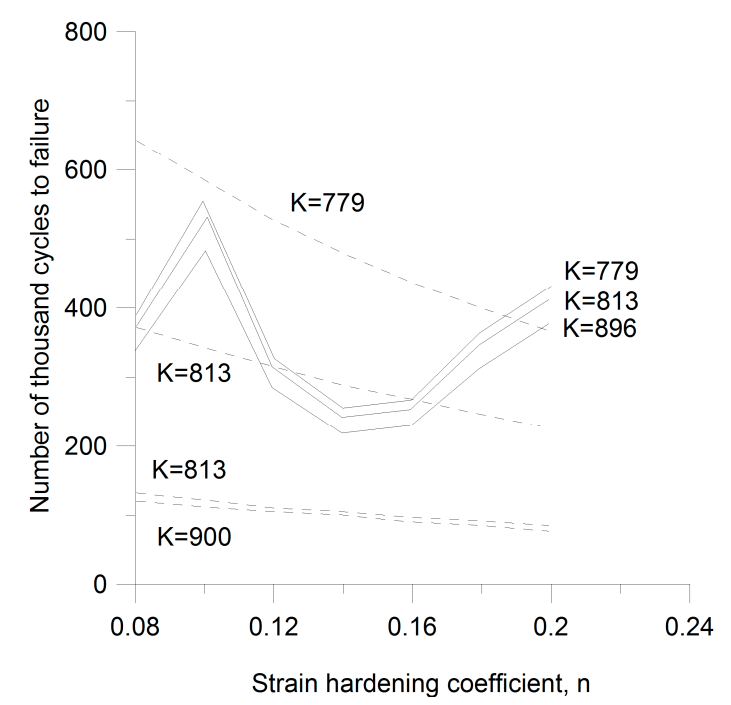

(b)

Figure 6. (a) Simulated fatigue and wear life versus strength coefficient after ref. [16]; (b) Simulated fatigue life for four different strengths coefficients versus the strain hardening coefficient after ref. [16]. Dashed line $=$ fatigue limit, solid line $=$ wear limit.

Lee et al. [16] concluded that for the same strength coefficient of the material the high-cycle fatigue tool life decreased as the strain hardening coefficient increased. However, the total amount of wear had local maximum and minimum values depending on the strain hardening exponent. 
In the coupling between the wear depth and the fatigue life, surface conditions are important as surface roughness influences the fatigue crack initiation. Wan et al. [17] developed and implemented a model for wear depth and surface roughness change in abrasive media finishing which has relevance to cold forming and abrasive tool wear. The basic assumption is that the wear has two components, on that is steady wear corresponding to the Archard wear type and a transient component. Wan et al. [17] derived a phenomenological model describing the local change in dimension, $h$, as well as the local change in surface roughness, $R_{a}$, as

Wear depth $h$

$$
h=a\left(R_{0}-R_{\infty}\right)\left(1-\exp \left(-\frac{k_{T} p_{a} v t}{H}\right)\right)+\frac{k_{S} p_{a} v t}{H}
$$

Surface roughness $R_{a}$

$$
R_{a}=\left(R_{0}-R_{\infty}\right) \exp \left(-\frac{k_{T} p_{a} v t}{H}\right)+R_{\infty}
$$

where $k_{T}, k_{S}$ are material constants, $H$ is material hardness, $p_{a}$ contact pressure, $v$ sliding/surrounding media speed (here the analogy would be work piece sliding speed, $t$ duration of sliding action), $R_{0}$ is initial surface roughness and $R_{\infty}$ is final attainable roughness.

\section{Material Properties and Implications for Tool-Life}

It is clear from the above examples of modeling that there are several important areas to cover in order to understand the uncertainties of tool life.

Simple relations as stress strain curves are the starting point for mechanical behavior. Stress strain relationships for common tool steels are shown in Figure 7a [2]. For different materials there is also a unique relation between tensile strength and hardness which is illustrated for common cold-work steels in Figure $7 \mathrm{~b}$. For fatigue there also exists a generic relationship for the material itself, for different load cases as illustrated in Figure 7c and for wear, Figure 7d [18].

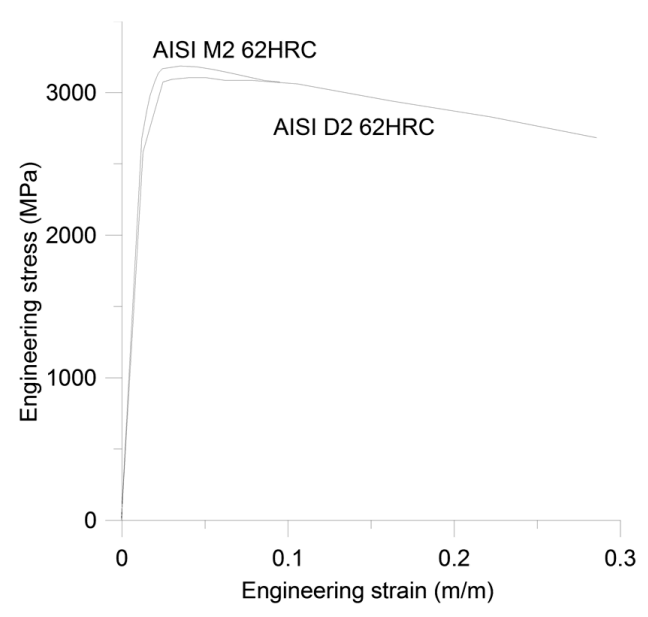

(a)

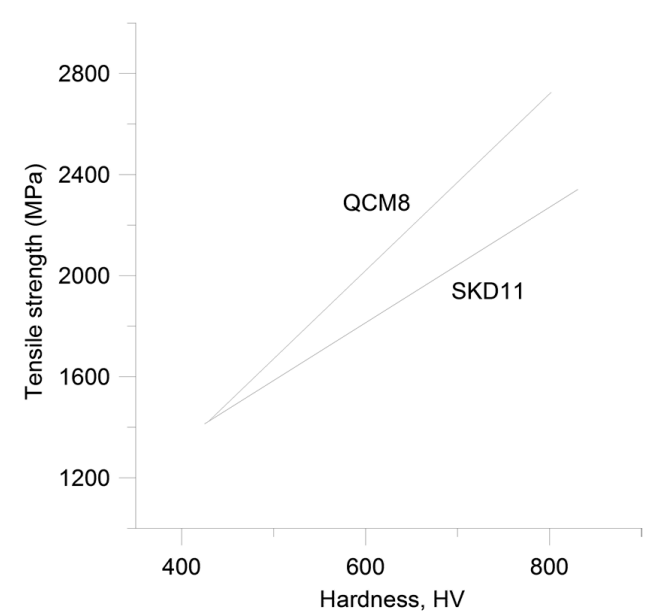

(b)

Figure 7. Cont. 


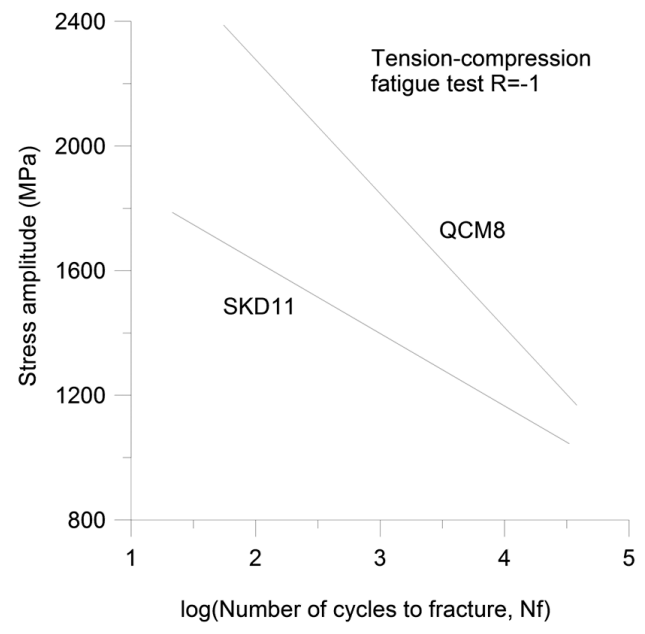

(c)

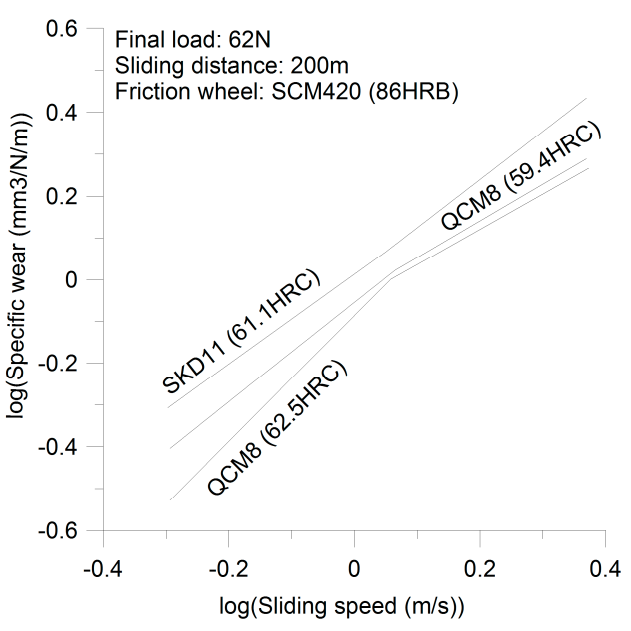

(d)

Figure 7. (a) Stress strain curves for M2 and D2 tool steels after ref. [2]; (b) Relation between hardness and tensile strength for SKD11 (D2-type) and QCM8 (low Cr version of SKD11) after ref. [18]; (c) Relation between stress amplitude and fatigue life for tension-compression fatigue for SKD11 (D2-type) and QCM8 (low Cr version of SKD11) after ref. [18]; (d) Relation between sliding speed and wear rate for SKD11 (D2-type) and QCM8 (low Cr version of SKD11) after ref. [18].

These tests are made under constant and well controlled conditions. In the real tool these conditions are not as well defined and are changing during use. There also exists a spread in properties depending on where the material fails that is both batch and supplier dependent. In an effort to capture the probabilistic nature of the tool life Engel [19] concluded that the task to predict tool life depends on 2 steps

- the determination of load and

- the determination of strength

The key reasons for the scatter on the other hand is due to

- the deviations from perfect geometry;

- uncertainties in the state of pre-stressing of the die;

- uncertainties in the strength of the material; and

- deviations from ideal surface conditions.

Engel [19] concluded that if the tool life is considered as the decisive criterion for tool layout and for improving the tool performance, the stochastic characteristics of this parameter have to be taken into account. Due to the tool life being influenced by deterministic as well as stochastic factors, the most promising way to solve the problem is the combination of mechanical/numerical and statistical analysis. The approach capable to derive a tool-life with a well-defined level of confidence is comprised of the following steps:

- quantifying the stochastic characteristics of primary parameters of influence, such as for example the surface topography;

- $\quad$ establishing the distribution functions of load and strength; and

- determining the failure probability and its evolution.

\subsection{Material Fatigue Resistance}

The material fatigue resistance is clearly influenced by the type and nature of the particles inside the material and as well as particle near the surface of the specimen and by the surface roughness. 
The individual influence and the origin of failure strongly depend on the stress level and number of cycles to failure as different crack initiation mechanisms are active. Sohar et al. [20] clearly illustrated this experimentally for a high chromium alloyed tool steel in giga-cycle fatigue, Figure 8a,b. The influence of carbides and the effect of surface residual stresses, resulting from heat treatment or from the grinding/polishing process, on the fatigue behavior in the giga-cycle regime of ingot metallurgy produced D2 type tool steel were examined. Residual stresses were found to be responsible for the occurrence of two failure modes:

- Internal cracks initiating at large primary carbides (clusters) were observed in the cycle number range of $10^{5}-10^{6}$ cycles,

- In the giga-cycle regime near-surface cracks originating at primary carbides caused failure, which was related to degradation of the RS by cyclic loading.

In the absence of considerable residual stresses predominantly near-surface crack initiation was obtained. It should here be noted that with a high compressive residual stress internal carbides are the main cause for fatigue crack initiation. Understanding the particle size distribution of carbides and inclusions are thus clearly important.

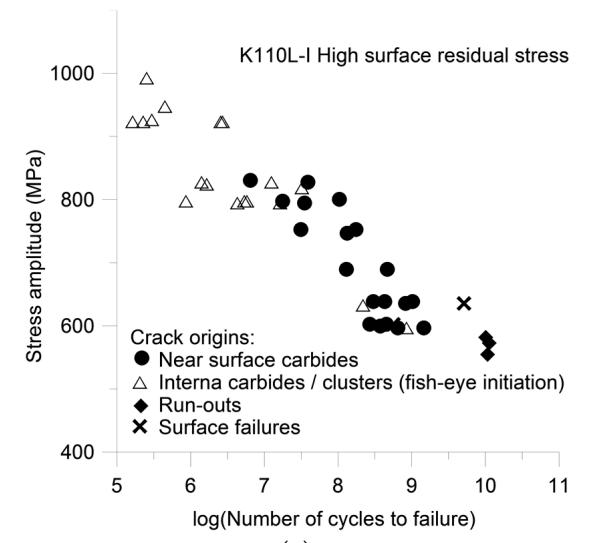

(a)

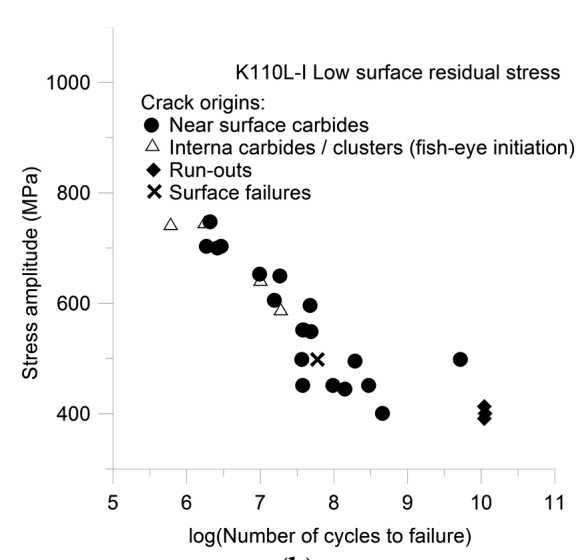

(b)

Figure 8. (a) Fatigue data of ultrasonic high cycle fatigue tests for AISI D2 steel K110L-I with high surface residual stress after ref. [20]; (b) Fatigue data of ultrasonic high cycle fatigue tests for AISI D2 steel K110L-I with low surface residual stress after ref. [20].

Elvira et al. [21] showed a similar relation for ultra clean high strength steel where inclusions and microstructural features are the dominant reasons for crack initiation at lower number of cycles, Figure 9.

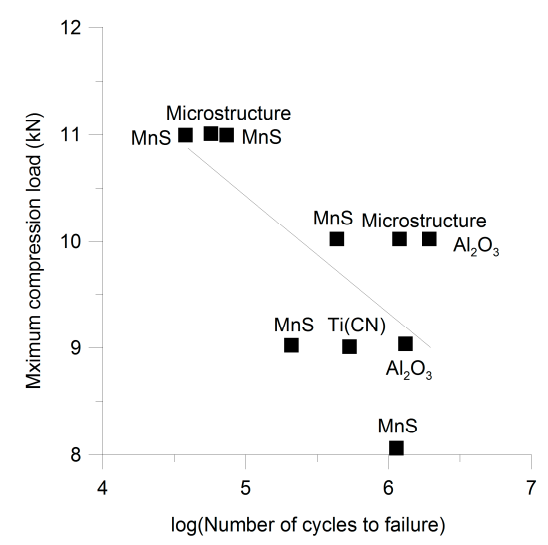

Figure 9. Reasons for fatigue failures in 100Cr6 high strength steel (martensitic bearing steel) after ref. [21]. 
The importance of surface inclusions was further emphasized by Meurling et al. [22]. They clearly illustrate in Figure 10 the importance of microstructual features such as carbides and carbide clusters at the higher strength. The relation between the carbides and inclusions are consistent with the findings of Haglund [23] that concluded that:

- The highest stress concentrations are found in the transversal direction of MnS inclusions while in the parallel direction the stress concentration is very small.

- The second highest stress concentration is found around $\mathrm{Ti}(\mathrm{C}, \mathrm{N})$ particles due to the square geometry.

- $\mathrm{Al}_{2} \mathrm{O}_{3}$ particles generated the smallest stress concentrations due to the rounded geometry.

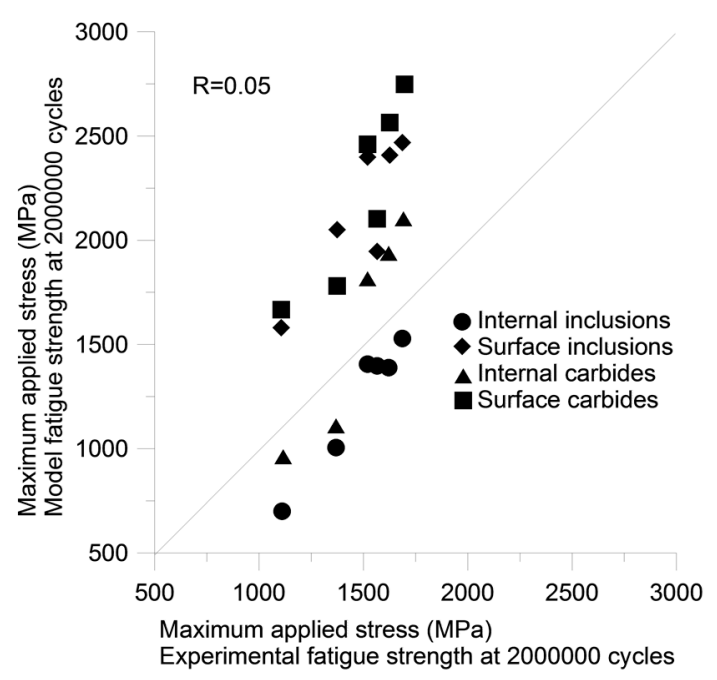

Figure 10. Failure reasons at various experimental strengths after ref. [23].

From this it is understood that in addition to understanding the particle size distribution, it is also important to understand the probability of finding particles in the surface of the part or specimen.

Sohar et al. [20] used a simple approach to assess the number of surface carbides in a materials based on the total number of carbides, $N_{C a r, V}$, in the test specimen are

$$
N_{C a r, V}=n_{\text {Car }} V_{\text {test }}
$$

With, $n_{\text {Car }}$, as particle density and, $V_{\text {test }}=\frac{\pi d^{2} l}{4}$, as specimen volume (cylindrical shape of diameter $d$ and length $l$ ).

The number of carbides in a thin surface volume, $V_{s l}$, can be expressed as

$$
N_{C a r, s l}=n_{C a r} V_{s l}
$$

with

$$
V_{s l}=\pi d l d_{s l}
$$

where $d_{s l}$ is the thickness of the surface layer.

For the carbides it is reasonable to assume that

$$
d_{s l}=d_{C a r}
$$

The ratio between the bulk and surface carbides can thus be expressed as

$$
\frac{N_{C a r, s l}}{N_{C a r, V}}=4 \frac{d_{C a r}}{d}
$$


The probabilistic nature of the fatigue failure is intimately connected to the variation in life-span as illustrated in Figures 8-10. Meurling et al. [22,24] developed a model based on the particle size distribution, divided into inclusions and carbides, in the material to estimate the life span of tool materials. The starting point is the size distributions of carbides and inclusion as illustrated in Figure 11a,b.

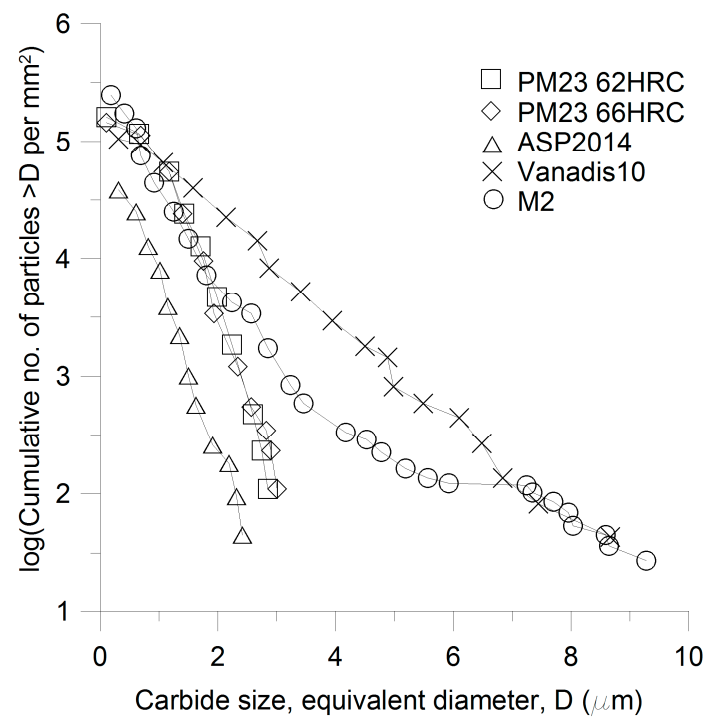

(a)

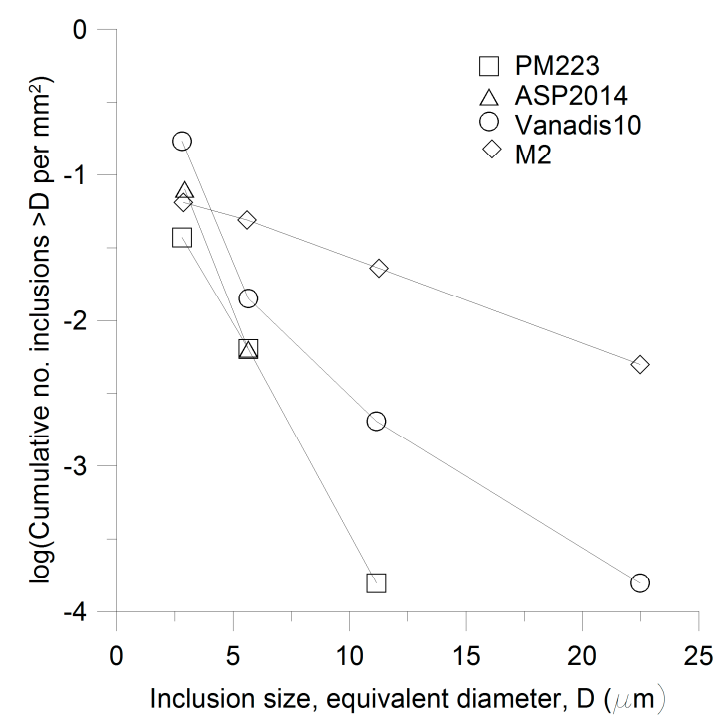

(b)

Figure 11. (a) Carbide size distribution for various tool steels [22]; (b) Inclusion size distribution for various tool steels [22].

In fatigue the stress amplitude, $\Delta \sigma$, is important and the interior particles of a diameter, $D$, acts as stress intensifiers as

$$
\Delta K_{I}=2 \Delta \sigma \sqrt{\frac{D}{2 \pi}}
$$

The stress intensity factors, $\Delta K_{I}$, found for inclusions and carbides are shown in Figure 12a,b. Clearly the intensity factors mainly lie in a band above $4 \mathrm{MPa} \sqrt{ } \mathrm{m}$, which is the common threshold stress intensity for crack propagation, $\Delta K_{t h}$, in the steels studied excluding the M2 high-speed steel.

To account for the stochastic nature of fatigue analysis, Meurling et al. [22] developed a model based on the following assumptions:

- Around all particles such as carbides and inclusions, cracks exist of equal size as the initiating particles.

- An existing crack will not grow unless the stress intensity at its tip exceeds the stress intensity threshold for crack propagation.

- If there exists at least one crack for which the stress intensity exceeds the threshold value, then this crack will eventually propagate to cause failure of the specimen. 


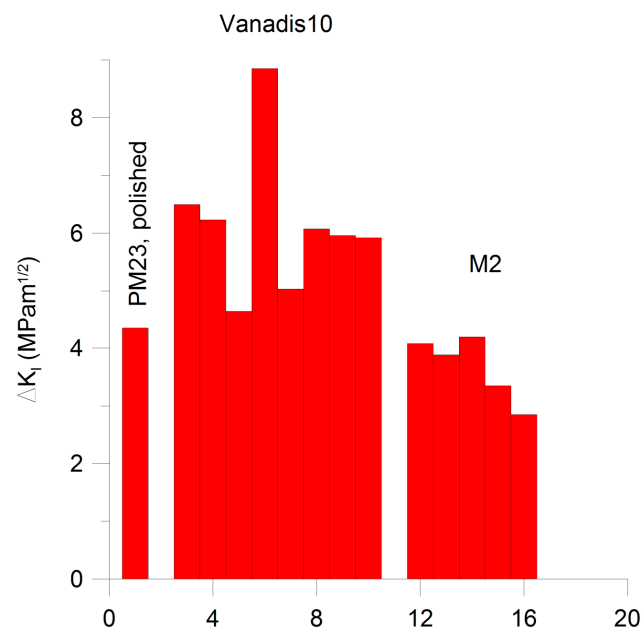

(a)

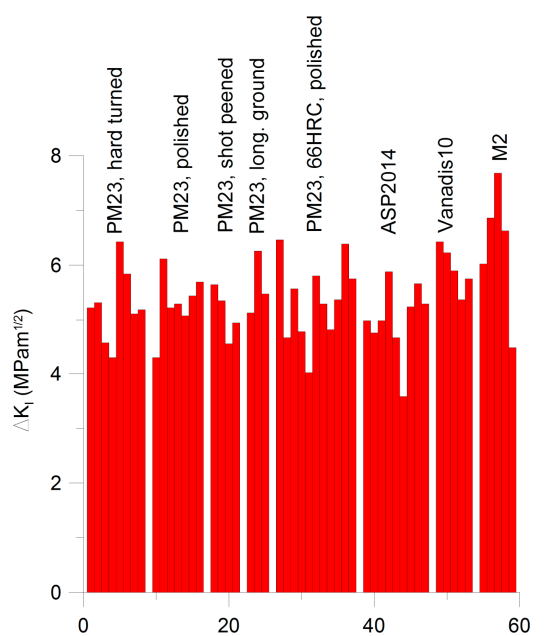

(b)

Figure 12. Stress intensity factors (a) found in three types of tool steels based on carbides after ref. [22];

(b) found in four different tool steels at different conditions, based on inclusions after ref. [22].

Based on the different inclusion and carbide populations, a defect is defined as critical if its stress intensity exceeds the threshold for propagation, $\Delta K_{t h}$, calculated through Equation (25), coupled with data as shown in Figure 12a,b. The critical size of a particle, $D_{c}$, as shown is therefore

$$
D_{c}(\Delta \sigma)=2 \pi\left(\frac{\Delta K_{t h}}{2 \Delta \sigma}\right)^{2}
$$

Meurling et al. [22] then used Poisson statistics to derive an expression for the number of critical defects, $\lambda_{c}$, in the material as

$$
\lambda_{c}=f \sqrt{\frac{2 k^{3}}{\pi}} \int_{V} \int_{D_{c}}^{\infty} D^{-\frac{1}{2}} e^{-k D} d D d V
$$

Here $f$ and $k$ are constants defining the particle distribution. Knowing this expected number, the probability of finding a certain number of critical defects, $n$, in a volume of material can be expressed using Poisson's statistics

$$
p(n)=\frac{\lambda^{n}}{n !} e^{-\lambda}, n=1,2,3, \ldots
$$

According to assumptions above one can then say that the specimen will fracture if $n$ equals any number except zero, i.e., at least one critical defect exists. Therefore the fracture probability equals one minus the probability that there exists no $(n=0)$ critical defects:

$$
P_{f}=1-e^{-\lambda_{c}}
$$

For the total failure probability due to the combination of all considered defects the following expression is used:

$$
P_{f}^{t o t}=1-e^{-\sum_{i} \lambda_{c, i}}
$$

where $i$ is the sum over all types of considered defects which for Meurling et al. [22] case would be pcarbides and inclusions. The critical criterion for fracture was then set to $P_{f}^{\text {tot }}=0.5$. Meurling et al. [22] did not change the carbide distributions for surface carbides but rather only increased the fatigue life limit with the measured residual stress to obtain the measurement for surface particle induced failure. The work by Meurling et al. [22] concluded that fatigue crack initiation occurred at inclusions situated 
inside the specimens in most cases. Carbides also caused failures in the M2 grade and in the carbide rich grade VANADIS10. For longitudinally ground PM23, specimens also fractured from carbides in the surface. For shot peened PM23, specimens also fractured from deformed turning-grooves from the hard turning. The threshold for propagation of cracks at inclusions and carbides controlled the fatigue strength.

Important to the fatigue life is not only the inclusions and carbides but also the way the surface is prepared. Fredriksson et al. [25] investigated the effect on EDM conditions on the formation of surface defects and fatigue life of the cold work steel CALMAX (CLX) and the high speed steel ASP2023 (A23). The fatigue tested conditions were EDM3 (Rough EDM (1.3 J) and fine EDM (0.09 J)), and EDM6 (Rough EDM $(0.24 \mathrm{~J})$ medium EDM $(0.09 \mathrm{~J})$ and fine EDM $(0.022 \mathrm{~J}))$. The resulting crack depths and pore diameters are found in Figure 13a,b. The corresponding fatigue life is shown in Figure 14a,b. Fredriksson et al. [25] concluded that the conditions in EDM6 resulted in smaller crack depth than EDM3 significantly improving the fatigue life of the specimen. From Figure 14a,b it is also clear that as the fatigue life was improved the scatter of the data increased. The fact that the scatter is greater for ASP2023 than for CALMAX is due to a more complex interaction between the carbides and the crack propagation.

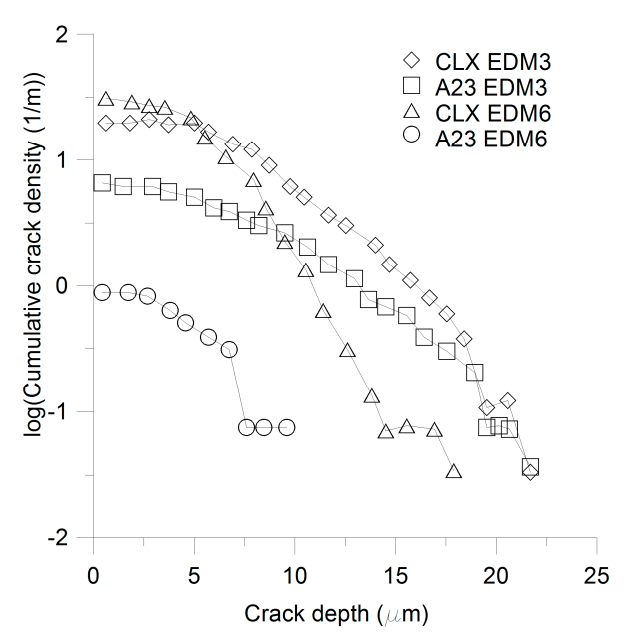

(a)

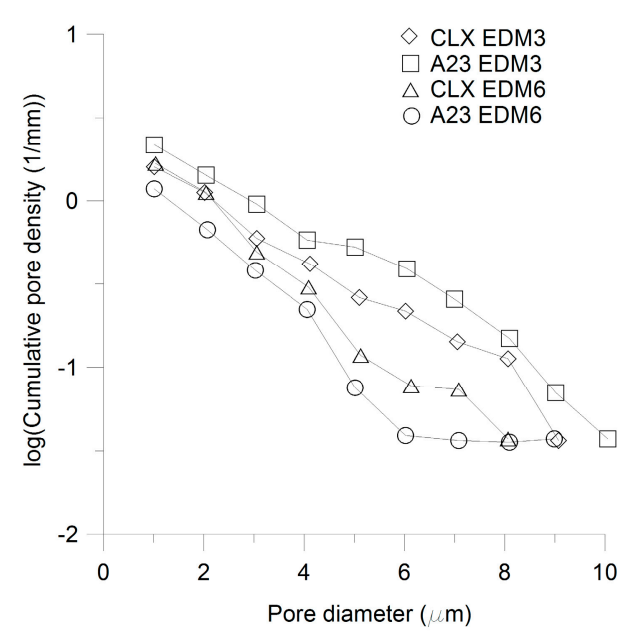

(b)

Figure 13. Defect distribution under different conditions for CALMAX(CLX) and ASP2023(A23), (a) cracks, after ref. [25] (b) pores after ref. [25].

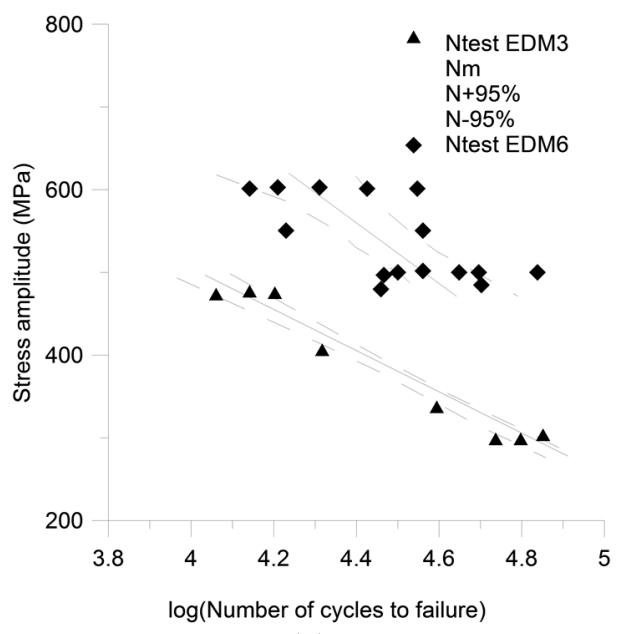

(a)

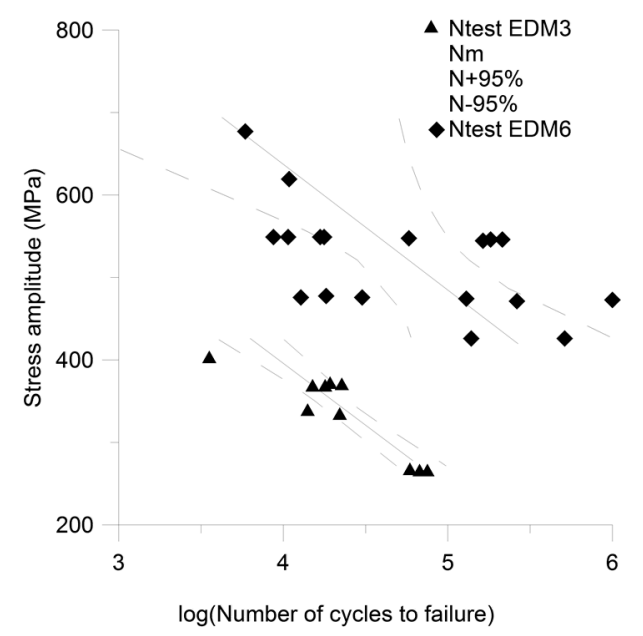

(b)

Figure 14. Fatigue life under different conditions (a) CALMAX(CLX) (b)ASP2023(A23) [25]. 
Methods like laser shot peening have been applied success fully to change the failure mode from crack propagation to flaking, commonly viewed as a less aggressive form of failure. One reason was the generation of very deep compressive stress [26]. Similarly, surface texturing using lasers have been tested with life extensions up to $170 \%$ though improved lubricant retention $[27,28]$.

\subsection{Material Wear}

In the models discussed above it is clearly understood that the wear behavior of the material is as important as the fatigue behavior. Wear is a subject well studied and the current work will focus on particular issues related to tool materials. In the modeling attempts above the key factor reducing the wear is hardness. The material dependent proportionality constants used in the modeling are strongly influenced by the nature of the contact which in turn is more or less dictated by the microstructure and how it wears. It is important to understand the type and nature of the microstructural constituents as these determine the hardness. Bergman et al. [29] studied the tribological properties of powder metallurgy (PM) based high speed steels (see Table 2). In these tool steels primary carbides are even harder than the matrix $(1500-2800 \mathrm{Hv})$

Table 2. Nominal chemical composition of the investigated materials (wt. \%) and Microstructural constituents as vol \% and average size of primary carbides $(\mu \mathrm{m})$, and bulk hardness for the high speed steels (HSS's) after ref. [29].

\begin{tabular}{|c|c|c|c|c|c|c|c|c|}
\hline Material & $\mathrm{C}$ & $\mathrm{Si}$ & Mn & $\mathrm{Cr}$ & Mo & $\mathbf{W}$ & $\mathbf{V}$ & $\mathrm{Nb}$ \\
\hline ASP2014 & 0.75 & 0.3 & 0.4 & 4.1 & 3.0 & 3.0 & 1.0 & 1.0 \\
\hline $\mathrm{E} \mathrm{M} 2^{\prime \prime}$ & 0.87 & 0.3 & 0.4 & 4.2 & 5.0 & 6.4 & 2.0 & - \\
\hline M2 PM & 0.87 & 0.3 & 0.4 & 4.2 & 5.0 & 6.4 & 2.0 & - \\
\hline ASP 23 CC & 1.28 & 0.3 & 0.4 & 4.2 & 5.0 & 6.4 & 3.0 & - \\
\hline ASP 2023 & 1.28 & 0.3 & 0.4 & 4.2 & 5.0 & 6.4 & 3.0 & - \\
\hline ASP 2053 & 2.50 & 0.3 & 0.4 & 4.2 & 3.0 & 4.0 & 8.0 & - \\
\hline \multirow[t]{2}{*}{ Material } & \multicolumn{5}{|c|}{ vol \% Primary Carbide } & \multicolumn{2}{|c|}{ Primary Carbide Diameter } & Bulk Hardness \\
\hline & \multicolumn{2}{|c|}{$\mathrm{M}_{6} \mathrm{C}$} & MC & \multicolumn{2}{|c|}{$M_{6} C+M C$} & MC & $\mathrm{M}_{6} \mathrm{C}+\mathrm{MC}$ & $(\mathrm{HVm})$ \\
\hline ASP2014 & \multicolumn{2}{|c|}{$\mathrm{a}$} & $2.9 \pm 0.4$ & \multicolumn{2}{|c|}{$2.9 \pm 0.4$} & 0.5 & 1.7 & $830 \pm 10$ \\
\hline E M2 & \multicolumn{2}{|c|}{$8.1 \pm 3.2$} & $\mathrm{a}$ & \multicolumn{2}{|c|}{$8.1 \pm 3.2$} & $3.2^{b}$ & $10.5^{\mathrm{b}}$ & $930 \pm 20$ \\
\hline M2 PM & \multicolumn{2}{|c|}{$10.0 \pm 1.5$} & a & \multicolumn{2}{|c|}{$10.0 \pm 1.5$} & 2.5 & 5.4 & $900 \pm 20$ \\
\hline ASP 23 CC & \multicolumn{2}{|c|}{$6.3 \pm 0.7$} & $6.2 \pm 0.8$ & \multicolumn{2}{|c|}{$12.5 \pm 1.5$} & 3.1 & 4.2 & $900 \pm 10$ \\
\hline ASP 2023 & \multicolumn{2}{|c|}{$8.1 \pm 0.6$} & $5.4 \pm 0.9$ & \multicolumn{2}{|c|}{$13.5 \pm 1.5$} & 1.2 & 2.2 & $930 \pm 20$ \\
\hline ASP 2053 & \multicolumn{2}{|c|}{-} & $16.2 \pm 1.4$ & \multicolumn{2}{|c|}{$16.2+1.4$} & 2.4 & 2.7 & $920 \pm 20$ \\
\hline
\end{tabular}

Conventionally produced a Only small amounts $(<1 \%)$, not possible to separate MC from M6 carbides with reasonable accuracy. ${ }^{b}$ The primary carbides form streaks. ${ }^{c}$ Different process parameters for ASP 23 CC give a different carbide size compared to ASP 2023, despite identical chemical compositions.

The main conclusions were that abrasives significantly harder than primary carbides of the HSS, hardness and ductility of the matrix controlled the wear rates. A consequence is then that two and three body abrasion rates showed only small variations with volume fraction, size and type of primary carbides. Abrasive or erosive particles are commonly softer than the primary carbides of the HSS. A positive effect on both abrasive and erosive wear resistance with an increased volume fraction of primary carbides will thus also be obtained [29]. For direct contact between the tool and work piece a high two-body abrasion resistance is associated with large and hard primary carbides in combination with comparably soft abrasives [29,30].

In general it is not so common to use uncoated dies. As the work piece size is reduced the contact pressure goes up and the risk of galling and other effects increase, in particular under microforming conditions. The influence of surface coatings and coating properties are equally important to the tool performance and are reviewed in the next section. 


\section{Surface Coatings}

Dohda et al. [31] investigated the application of hard coatings to die in dry ironing process by strip-ironing type tribo-simulator. They found that DLC-Si coating has the lowest friction coefficient and is characterized by the absence of galling when compared to $\mathrm{CrN}$ coating (see Figure 15a,b).

Takaishi et al. [32] investigated the effect of surface coatings of blanking die in a bid to reduce the use of lubrication. Their study adopted the use of diamond-like coatings, electric discharge coatings, the cryogenic process heat treatment and a combination of surface coatings and the cryogenic process. They could show (Table 3) that surface coatings and heat treatment of blanking die were effective and efficient for extension of blanking die life under no lubrication condition.

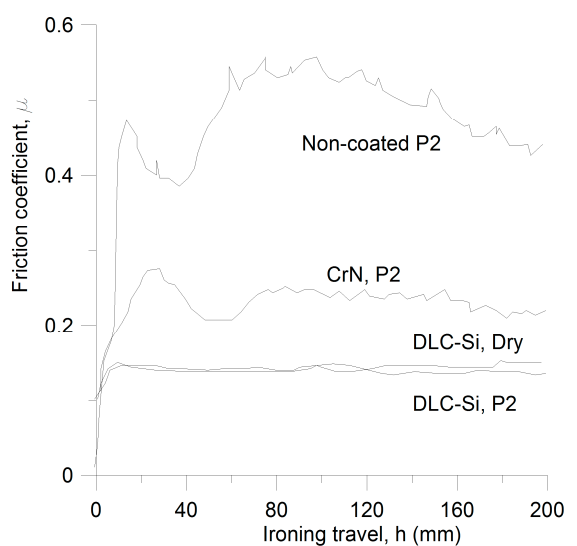

(a)

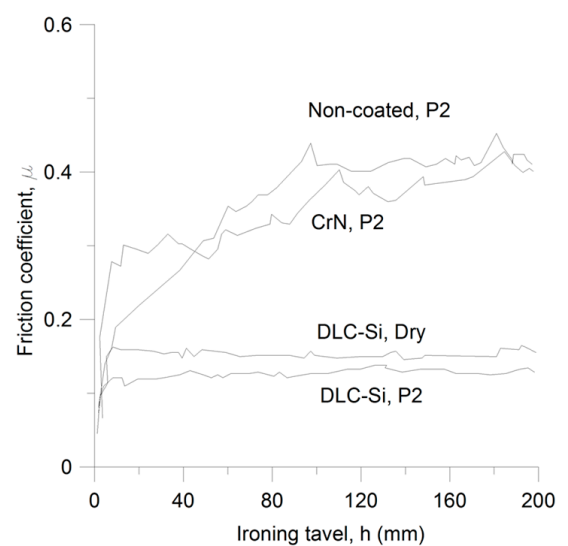

(b)

Figure 15. Variation of friction coefficient during ironing with a 20\% reduction (a) SPFC590, after ref. [31]; (b) C2801-1/4H after ref. [31].

Table 3. Experimental results from ref. [32].

\begin{tabular}{ccccccc}
\hline $\begin{array}{c}\text { Die } \\
\text { Material }\end{array}$ & $\begin{array}{c}\text { Surface } \\
\text { Coating }\end{array}$ & $\begin{array}{c}\text { Thickness of } \\
\text { Coating }(\mathbf{m m})\end{array}$ & $\begin{array}{c}\text { Heat } \\
\text { Treatment }\end{array}$ & $\begin{array}{c}\text { Number of } \\
\text { Blankings }\end{array}$ & $\begin{array}{c}\text { Extension } \\
\text { Ratio }\end{array}$ & $\begin{array}{c}\text { Damage of Die } \\
\text { Material }\end{array}$ \\
\hline SKD11 & None & - & Normal & 7000 & 1.00 & None: worn out \\
SKD11 & None & - & Normal+CP & 14500 & 2.07 & None: worn out \\
SKD11 & PVD Me-DLC & 0.002 & Normal & 23519 & 3.36 & Small chipping \\
SKD11 & PVD DLC & 0.002 & Normal & 18413 & 2.63 & None: worn out \\
SKD11 & PVD DLC & 0.002 & Normal & 13000 & 1.86 & Peeling \\
SKD11 & PVD DLC & 0.005 & Normal & 12000 & 1.71 & Peeling \\
SKD11 & ED-coat & 0.01 & Normal & 27500 & 3.93 & None: worn out \\
SKD11 & ED-coat & 0.01 & Normal+CP & 20100 & 2.87 & Chipping \\
SKD11 & ED-coat & 0.01 & Normal+CP 3 & 21900 & 3.13 & Chipping \\
SKD11 & ED-coat & 0.01 & Normal+CP 3 & 62000 & 8.86 & None: worn out \\
HSS ${ }^{1}$ & None & - & Normal & 24000 & 3.43 & None: worn out \\
HSS ${ }^{1}$ & ED-coat & 0.01 & Normal & 8300 & 1.19 & Chipping \\
VS ${ }^{2}$ & ED-coat & 0.01 & Normal & 15667 & 2.24 & Chipping \\
\hline
\end{tabular}

${ }^{1}$ HSS: High Speed Steel made through powder metallurgical processing. ${ }^{2}$ VS: Chromium-VanadiumMolybdenum powder metallurgical processed tool steel. ${ }^{3} \mathrm{CP}$ : Cryogenic Processing.

Tsuchiya et al. [33] conducted metal forming type tribological tests to evaluate the adhesion performance of DLC-Si coating. It was found that the coating had the lowest friction coefficient under a wide range sliding velocities, good anti-galling properties in backward extrusion test and good anti-flaking properties with preprocessing and as a coating on hard based metal.

Takatsuji et al. [34] investigated the validity of using high-strength/low friction die coatings to improve the tribological characteristics observed in micro extrusion. It was shown that the DLC-Spatter-coating produces the least friction and has the lowest extrusion force. 


\subsection{Characterization of General Coatings}

Thin, hard coatings deposited by physical vapour deposition (PVD), chemical vapour deposition (CVD) or plasma-assisted chemical vapour deposition (PACVD) onto tools of complex geometry to improve the tribological performance for engineering applications are increasingly widespread. The performance of the coatings usually depends on the fundamental properties of the coating and substrate used. Characteristics of the coatings mechanical properties such as hardness are usually the focus when new tribological coatings are developed. The characterization of the intrinsic mechanical properties of coatings and composite is also important. Figure 16 illustrates the general correlation between coating deposition parameters and the tribological response of the generated coating. Some techniques frequently used for the characterization of a few fundamental coating properties are listed in Table $4[35,36]$.

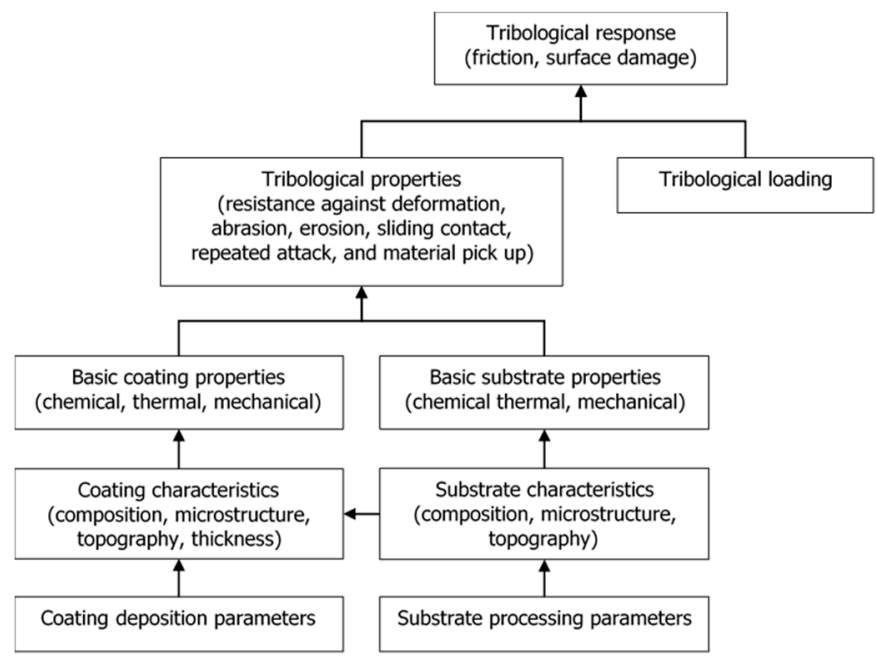

Figure 16. General relation between coating deposition and tribological response [36].

Table 4. Important coating properties and methods used to obtain them [35,36].

\begin{tabular}{ll}
\hline Coating Property & Characterization Method(s) \\
\hline \multirow{3}{*}{ Chemical composition } & Energy dispersive X-ray spectroscopy (EDX) \\
& Auger electron spectroscopy \\
& Glow discharge optical emission spectroscopy (GDOES) \\
\hline \multirow{2}{*}{ Microstructure and morphology } & Transmission electron microscopy (TEM) \\
& Scanning electron microscopy (SEM) \\
& Light optical microscopy \\
& X-ray diffraction \\
\hline \multirow{2}{*}{ Residual stress state } & X-ray diffraction \\
& Substrate deflection \\
\hline \multirow{2}{*}{ Hardness } & Ball grinding \\
& Cross-section microscopy \\
& X-ray fluorescence \\
\hline Adhesion to substrate & Extrapolation \\
\hline & Theoretical models \\
Fracture toughness & Scratch adhesion testing \\
& Indentation \\
& Microscopy observation of crack patterns \\
& Acoustic emission \\
& Bend test in Scanning electron microscope \\
& Vibrating reed \\
& Membrane \\
& Bulge \\
& Beam bending \\
& Indentation \\
& Tniaxial tensile \\
\hline & \\
& \\
& \\
&
\end{tabular}


The use of low temperature TiN coating (deposited at $200{ }^{\circ} \mathrm{C}$ ) gives a significant increase in hardness and residual compressive stress as compared to standard temperature coating (deposited at $400{ }^{\circ} \mathrm{C}$ ) according to a study done by Gahlin et al. [37]. They found that this increase is attributed to a sharp decrease in grain size and an increased micro strain for the low temperature coating due to poor quality of the low temperature TiN coating in combination with the high residual compressive stress. They found that for low temperature $\mathrm{CrN}$ coatings, the mechanical and tribological properties were comparable to that of coatings deposited at the standard temperature although a change in microstructure from a two phase structure to a single phase structure in the low temperature coating was observed.

\subsubsection{Young's Modulus}

PVD coatings often have a Young's modulus that surpasses that of the substrate and the coefficient of thermal expansion is usually lower, which affects the stress state in both the coating and the interface when a change in surface temperature occurs. The degree of the compressive residual stress will be reduced with a raise in the temperature which may lead to crack formation and coating delamination. A test method proposed by Hollman et al., which makes use of tensile testing, can be used to determine the Young's modulus of most PVD coatings in favor of the more traditional techniques such as the bulge test, the vibrating reed and membrane test $[36,38]$.

Coatings Young's modulus can be obtained from:

$$
E_{c}=\frac{k-E_{s} t_{s} w-k_{g}}{t_{c} w}
$$

where,

$k=$ slope of the tensile curve

$k_{g}$ = slope of force vs. strain for the two strain gauges (determined separately)

$E_{s}=$ Young's modulus of the substrate material (known)

$w=$ width of the coated sample

$t_{c}=$ thickness of the coating

$t_{s}=$ thickness of the substrate

Example of values for TiN can be seen in Table 5.

Table 5. Example of Young's modulus data for TiN [38].

\begin{tabular}{ccc}
\hline Coating Material & Substrate Thickness $(\boldsymbol{\mu m})$ & Young's Modulus (Coating) (GPa) \\
\hline TiN & 75 & $425 \pm 80$ \\
& 48 & $400 \pm 60$ \\
& 23 & $380 \pm 30$ \\
$\mathrm{NbN}$ & 75 & $350 \pm 50$ \\
\hline
\end{tabular}

\subsubsection{Residual Stress}

Coatings are often used to improve mechanical, thermal, chemical, optical and sometimes magnetic properties of surfaces. Interfacial delamination is usually the predominant failure mechanism due to the weak interface between the coating and the base material. High residual stresses present in the coatings will amplify the occurrence of interfacial delamination. Residual stresses are created in a good number of coatings as an effect of the manufacturing process whereby either a disparity in thermal expansion between the coating and substrate material generates considerable stresses which intensifies during cooling from a high deposition temperature or as a result of growth mechanisms or both [39]. 
The residual stresses experienced by PVD coatings on steel are usually compressive stresses that contributes to the occurrence of plastic deformation and micro-cracking which in turn affects the tribological response of the coated part [36].

The most common technique to determine residual stress is by using X-ray diffraction. Another approach is to use the curvature of a plate measured before and after deposition of the coating to calculate the residual stress $\sigma_{r \mathrm{~s}}$ using the Stoney equation $[35,36,40]$ :

$$
\sigma_{r s}=\frac{E_{s} t_{s}^{2}}{6\left(1-v_{s}\right) t_{c}}\left(\frac{1}{R_{a}}-\frac{1}{R_{b}}\right)
$$

where,

$\frac{E_{s}}{\left(1-v_{s}\right)}=$ biaxial modulus of the substrate

$t_{s}=$ substrate thickness

$t_{c}=$ coating thickness

$R_{a}=$ radius of curvature after coating deposition

$R_{b}=$ radius of curvature before coating deposition

Bromark et al. [41] found that multilayered Ti/TiN coatings show promise for combined wear and corrosion protection and that they also offer a means to modify the properties of tribological coatings which then can be used to control the coating's residual stress state. The wear characteristics of PVD $\mathrm{Ti} / \mathrm{TiN}$ multilayer coating, which were put through two-body abrasion and particle erosion, have been studied using diamond slurry and silicon carbide particles as abrasive medium and erodant, respectively. Abrasive wear rate of the Ti/TiN multilayer coatings was found to decrease with an increase in the relative amount of metallic Ti in the coatings. Their research also found that there is the likelihood that TiN in Ti/TiN coatings contain fewer impurities than conventional, homogeneous TiN coatings.

\subsubsection{Hardness}

In general, when the abrasive surface is harder than the wearing surface, the wear resistance in abrasive wear is closely related to hardness. However, if the wearing surface is much harder than the counter-surface, abrasion is no longer the wearing mechanism. In this case, ductility, chemical stability, fatigue resistance, or other properties affect the wear resistance more than the hardness. The extrapolation method is usually used by measuring the hardness of the coated specimen using different loads and extrapolating towards infinitely low loads [36]. The hardness can also be measured using a conventional Vicker's microhardness indenter and a load of 50 to $100 \mathrm{gf}[37,40]$, although some researchers believe that the measured hardness is not a good representation of the true hardness of the coating as it is usually influenced by the substrate material [35].

\subsubsection{Layer Adhesion}

A method for estimation of adhesion strength under similar situation of forging by combination of FEM and experiments was proposed by Hayakawa et al. [42] where a hard film coated spherical indenter made of tool material was indented into a flat workpiece material in the experiment while different values of critical interfacial normal and shear stress were used to perform the finite element analysis to obtain calibration curves by comparison of the the delamination length and indentation (Figure 17a-d).

Wang et al. [43] described a method to obtain stress-plastic strain curve by estimating the compression behavior of cemented carbides for cold forging dies using the Rockwell hardness test via the equations below (e.g., (32) and (33)). The correlation between the coefficient A or C and Rockwell hardness can be approximated by using a quadratic equation, Figure 18a,b.

$$
A=1.87 \times 10^{2} H R A^{2}-3.04 \times 10^{4} H R A+1.25 \times 10^{6}
$$




$$
C=5.68 \times 10^{3} H R A^{2}-9.44 \times 10^{6} H R A+3.93 \times 10^{7}
$$

The damage behavior of DLC-Si coating under high contact pressure was investigated by Kubota et al. [44] by conducting a series of experiments using the Vicker's hardness test. The effect of coating thickness on coating damage was observed from the coating and cross-section surfaces. During unloading materials flow to the cents in the upper regions with the possibility of shear cracking in the coating. Tensile stress will also develop at the substrate/coating interface, (see Figure 19).

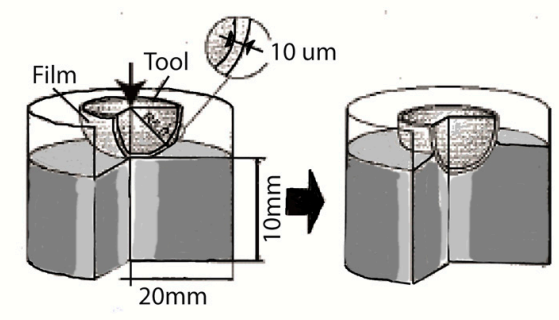

(a)

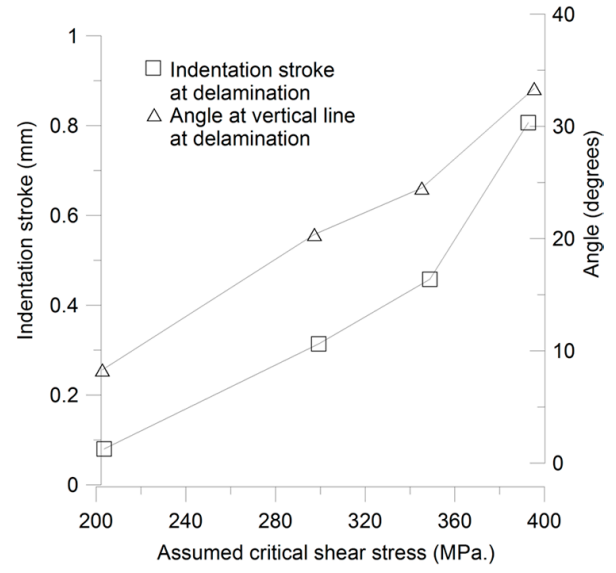

(c)

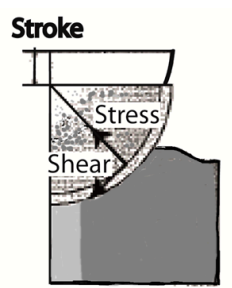

(b)

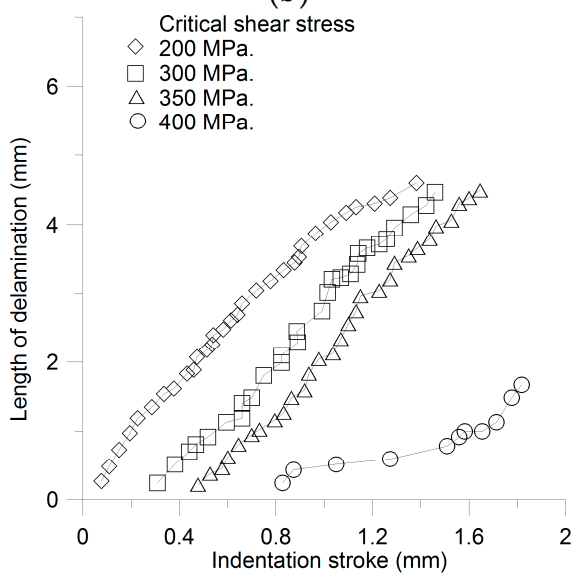

(d)

Figure 17. Illustration of layer adhesion testing, (a) Testing model; (b) stresses in the interface, after ref. [42] (c). Illustration of layer adhesion testing, Relation between initial delamination and assumed critical shear stress; (d) relation between length of delamination and indentation after ref. [42].

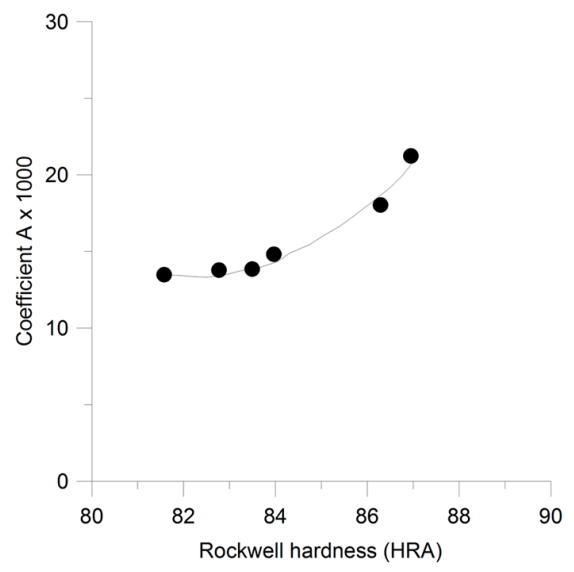

(a)

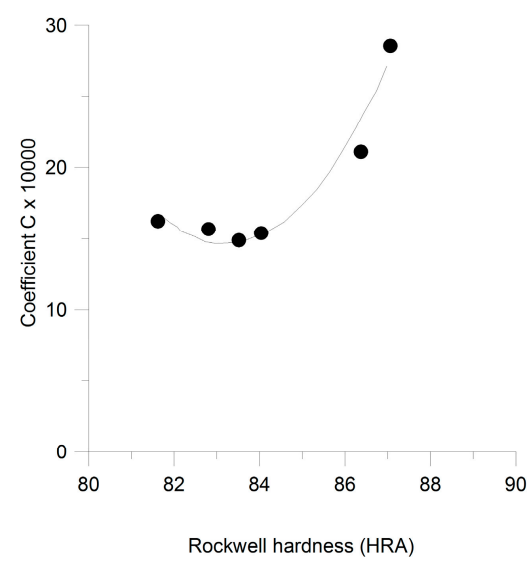

(b)

Figure 18. (a) Relationships between the hardness and the evaluated coefficient $\mathrm{A}$ and Rockwell hardness, after ref. [43]; (b) Relationships between the hardness and the evaluated coefficient $C$ and Rockwell hardness after ref. [43]. 


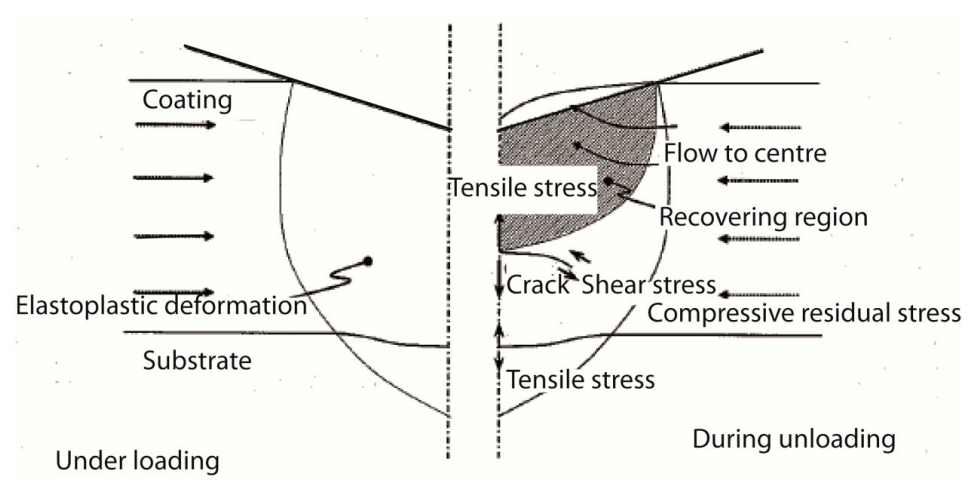

Figure 19. Model for coating fracture mechanism during indentation [44].

\subsubsection{Fracture Strength}

The coating's fracture toughness is an important parameter when choosing a coating, as the presence of crack initiation and propagation usually signals the start of coating failure. Fracture toughness of coatings can be obtained by introducing high loads of Vickers' indentations of at least $10 \mathrm{~kg}$ and determine the length of the cracks that appear in the corners of the indentation. The presence of extended cracks signifies a low fracture toughness and vice versa [35].

\subsection{Lubrication and Tribological Influence of Surface Condition and Coatings on Tool Life}

Large surface expansion and normal pressure in the tool/workpiece interface in combination with elevated tool temperatures have extremely severe effects on the tribological conditions in cold forging. The use of a conversion coating acting as a lubricant carrier in order to reduce friction is essential in such a case as conventional lubricants are inadequate under these conditions. The physical or chemical reaction of the lubricant to the surface of the workpiece results in better adhesion. Some recommended lubricants in cold forging of steel are shown in Table 6. However, the use of surplus amount of lubricants might cause entrapment of lubricants in the corners of the tool and in the workpiece surface resulting in severe intolerance and surface roughness on the tool and workpiece surface. Table 7 shows some advantages and disadvantages of the various lubricant systems [45].

Table 6. Recommended lubricant in cold forging of steel and approximate values of the friction coefficient [45].

\begin{tabular}{cccc}
\hline Process & Deformation & Lubrication & Friction Coefficient $\boldsymbol{\mu}^{*}$ \\
\hline Upsetting & Light & $\mathrm{None}$ & 0.2 \\
& Severe & $\mathrm{Mi}+\mathrm{EP}+\mathrm{FA}$ & 0.1 \\
& Light & $\mathrm{Ph}+\mathrm{SP}+\mathrm{Mi}+\mathrm{EP}+\mathrm{FA}$ & 0.1 \\
Ironing and open die extrusion & Severe & $\mathrm{Ph}+\mathrm{SP}$ & 0.1 \\
Extrusion & Light & $\mathrm{Ph}+\mathrm{Mi}+\mathrm{EP}+\mathrm{FA}$ & 0.05 \\
& Severe & $\mathrm{Ph}+\mathrm{SP}$ & 0.1 \\
& & $\mathrm{Ph}+\mathrm{MoS}_{2}$ & 0.1 \\
& & $\mathrm{Ph}+\mathrm{MoS}_{2}+\mathrm{SP}$ & 0.05 \\
\hline
\end{tabular}

Mi-mineral oil; EP-extreme pressure additive; FA-fatty additives; SP-soap; Ph-phosphate coating. ${ }^{*}$ Note: The values for the coefficient of friction are directional values, which are suited only for comparison between different lubricants and processes. 
Table 7. Advantages and disadvantages of different lubrication systems for cold forging of aluminium [45].

\begin{tabular}{|c|c|c|c|}
\hline Lubricant System & Lubricant Performance & Advantages & Disadvantages \\
\hline Grease & Moderate lubricity & Easy to handle & \\
\hline Phosphate coating + lubricant & Very good lubricity & $\begin{array}{l}\text { Low treatment temperature } \\
\text { Applicable to all aluminium alloys }\end{array}$ & $\begin{array}{l}\text { Very difficult bath control } \\
\text { Difficult disposal } \\
\text { Limited life time of bath }\end{array}$ \\
\hline $\begin{array}{l}\text { Aluminium fluoride } \\
\text { coating + lubricant }\end{array}$ & Excellent lubricity & $\begin{array}{l}\text { Short treatment time } \\
\text { Easy bath control } \\
\text { Applicable to all aluminium alloys }\end{array}$ & $\begin{array}{l}\text { Hazardous working } \\
\text { environment } \\
\text { High treatment temperature } \\
\text { Difficult disposal } \\
\text { Short life time of bath }\end{array}$ \\
\hline
\end{tabular}

Hanson et al. [46] investigated the adhesion and metal transfer of austenitic stainless steel against TiN under non-lubricated sliding contact. The interface between the TiN and the adhered stainless steel was investigated by TEM and the oxide layer emanating from the stainless steel surface was observed between the tool surface and the adhered stainless steel. They showed that samples oxidized at higher temperatures were less inclined to adhere than those oxidized at lower temperatures due to their higher thickness or a higher content of $\mathrm{Cr}$ at the surface.

The frictional properties and tendencies of counter material pickup were compared between a physical vapour deposited (PVD) TiB2 coatings and commercially available PVD TiN, TiAlN and TiCN. Berger et al. [47] investigated the possibility of the superior behaviour of the TiB2 coating experienced in severe sliding applications against aluminium alloys being extended to other materials with similarly poor tribological characteristics. The paper proved it possible to approximate the friction force from the width of the sliding tracks, Vickers hardness of the opposing material and simple plastic considerations. This estimation also confirmed the surprisingly low friction of all coatings against Ti alloys. TiB2 coating outperformed the commercially available coatings regarding friction, resistance against pick-up of counter material and smoothness in the contact area of both coating and counter material. This trend is attributed to the exceptionally high chemical resistance of TiB2 against aluminium.

\section{Surface Finish/Roughness}

The effects of substrate material on the erosion resistance of three dissimilar TiN coated tool steels were studied. Results showed that the carbide volume fraction and the impact toughness of the substrate material controlled the erosion rate of both the coatings and the substrates. Properties such as hardness and impact toughness of the substrate are imperative for the general tribological performance of a coating-substrate composite [48].

The critical nominal force during scratch testing on four different TiN coated tool steels was obtained to study the effect of pre-coating substrate surface topography. For the TiN coated high speed steels, the critical nominal force decreased with increasing surface roughness although no effect could be seen for the coated hot and cold worked steels. It thus can be assumed that the critical normal forces that are commonly cited as measures of the adhesion between good adhering coatings and their substrates are instead measures of the ability of the coatings to resist deformation [49].

Tribological evaluation on the influence of surface roughness and coating type on the galling properties of coated forming tool steel was investigated by Podgornik et al. [50] They found that the friction intensity and the aptitude of a material to prevent the pick-up of counter material were largely influenced by surface roughness. The study showed that with increasing smoothness of the substrate, the coated surface can withstand a higher critical load and thus polishing of a surface prior to deposition of a coating will increase the critical load for material transfer by reducing friction. 
The effect of different surface modification techniques on galling properties was investigated. The group considered the application of different grades of polishing, plasma nitriding and DLC coating on cold work tool steel and tribological evaluation work was done in a load-scanning test rig. The research found that with appropriate polishing of the tool surface, the inclination for galling to occur reduced significantly. They also found that the application of a carbon-based multilayer WC/C coating can sustain low friction and greatly increase the galling resistance even when there is a fairly high surface roughness. Hard TiN coating displayed high friction and low galling resistance when in contact with austenitic stainless steel while plasma nitride treatment on the tool surface after polishing enhanced galling properties by up to $40 \%$. It was suggested by Podgornik et al. [51] that a hard, low friction coating can be deposited by plasma nitriding being applied to the tool material to improve the load carrying capacity of forming tool steel followed by post polishing of the contact surface to remove any surface asperities. The influence of an excimer laser treatment of TiN-coated tool surfaces on their tribological behaviour in the field of cold forging was investigated by Popp et al. [52]. The results show that triological behavior of the tool surface can be improved if the textures are designed with proper geometry and size according to the process parameters, and this will lead to an increased tool life.

\subsection{Influence of Coatings on Fatigue Life}

The effect of low cycle fatigue on TiN coated high-speed steel and high chromium (12.6\%) high carbon cold work tool steel were studied by Kocanda et al. [53] Constitutive equations which can be applied in numerical modelling of TiN coated tool behavior were derived from results from experimental works where cyclic loading was strain controlled and stress-strain hysteresis loops were recorded for both workpieces. Maximum tensile stress amplitudes were obtained from stabilized loops and the corresponding strain amplitudes where cyclic stress-strain curves were plotted (Figure 20a,b).

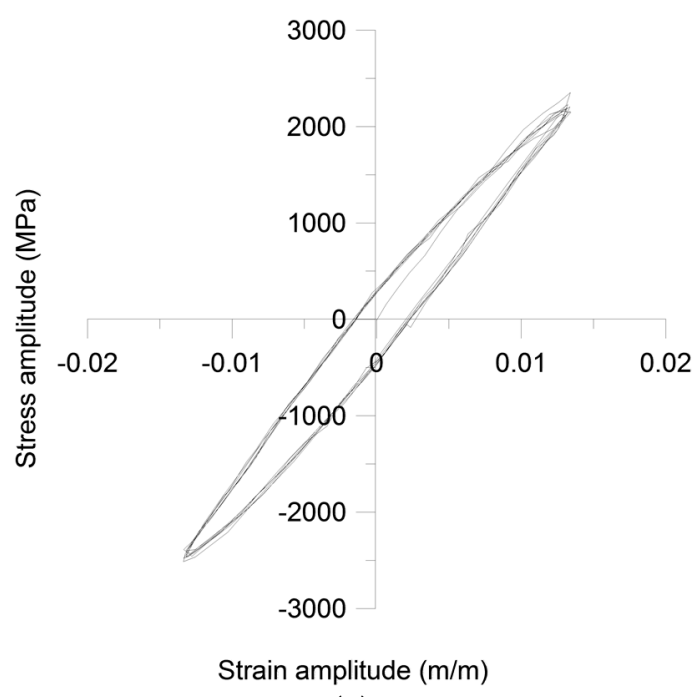

(a)

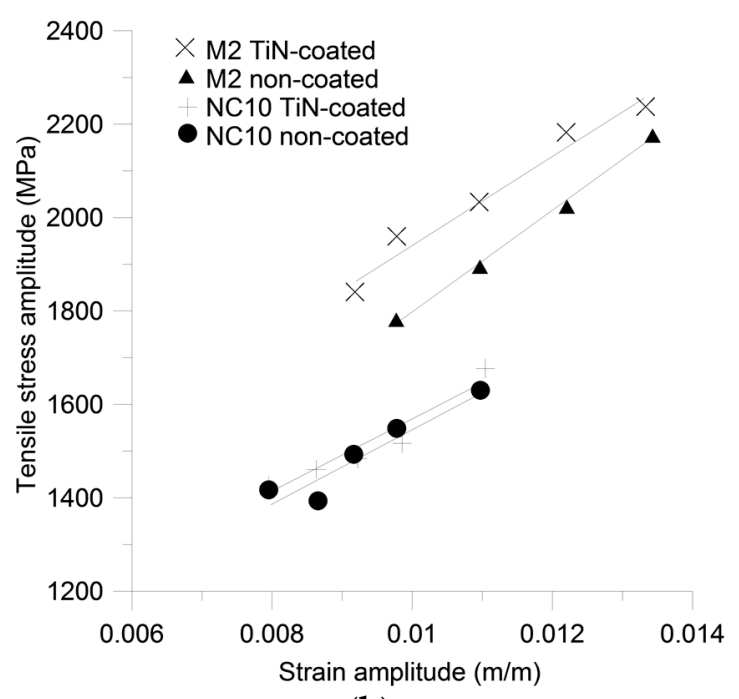

(b)

Figure 20. Material fatigue response (a) Hysteresis loop for non-coated M2 tool steel at a strain amplitude of 0.0135, after ref. [53]; (b) Material fatigue response, cyclic strain amplitude—strain curves after ref. [53].

The fatigue crack growth behavior of cemented carbide dies was investigated under the service load in the cold heading process of steel wire by Wang et al. [54]. The failure mode was identified as fatigue cracks and smaller chipping pits appearing at the very early stage when the die was under the chipping process stage. 
In general the introduction of an additional interface should reduce fatigue life of a well-controlled specimen. Baragetti [55] studied the effect of extremely thin films and their effect on fatigue. The benefits of thin coatings can be summarized as

- High hardness and wear resistance without affecting the dimensional tolerances of coated components,

- Suitability for coating small components,

- Good wear protection of specific geometries (e.g., sharp edges),

- Process capability to coat complex shaped components.

This is naturally under the provision that compressive residual stresses are introduced on the surface layer from the PVD deposition process that helps to increase the fatigue limit of coated structural components. Baragetti [55] concluded that:

- Fatigue test showed that the PECVD/SiO2 coating did not significantly affect the fatigue behavior of the base material with no change in initiation and propagation between the coated and uncoated specimen

- Fatigue crack propagation mechanisms in coated specimens are similar to uncoated specimen.

- Fatigue limit decrease by $10 \%$ with respect to uncoated material

\section{Surface Characteristics Change in Service and Influence on Wear Resistance}

Gåård et al. [56] assessed the galling resistance of various tool steels against dual phase high-strength carbon steel using a slide-on-flat-surface (SOFS) tribometer. The tools' chemical composition, microstructure and heat treatment were found to have a significant influence on the tools' behaviour during the entire wear process. Three frictional regimes were identified and characterized during sliding: Regime 1, with relative stable frictional conditions; Regime 2, with an increase in friction due to macroscopic abrasive scratching of the sheet surface; and Regime 3, with high and unstable frictional conditions due to adhesive wear of the sheet of the entire contact area.

Different lab test methods with respect to their ability to guide in the selection of material resistance to gouging abrasive wear were investigated by Bryggman et al. [57] The pin-on-disc test was carried out to study the resistance of the test material to low stress abrasion; multiple pass single tip grooving was used to evaluate the material response to cyclic abrasion under low stress, where the fatigue and adhesion properties of the affected surface layers governs the wear rate under these conditions. Single pass grooving was carried out to evaluate the energy consumption during abrasion and structure studies utilized light optical microscopy, scanning electron microscopy and micro-hardness measurements carried out on prepared metallographic sections parallel to the grooving direction and normal to the worn surfaces, to study the affected material underneath the worn surfaces and groove bottoms. It was found that the single pass pendulum grooving mimicked the wear of bucket teeth during the loading of wet blast stone most closely.

Jacobson et al. [58] presented briefly a selected number of surface modifications tribosystem to illustrate the prediction of friction and wear properties of a material in a given tribological situation based on the four main categories of surface modifications shown in Figure 21. Their study based on the four surface modification categories highlighted the importance of surface modifications and tribofilms analyses being included in the analyses of tribological components or tribological tests as their importance is often overly underestimated which can lead to drastic consequences. The understanding of surface modifications tribosystem will enable design of materials, coatings, lubricant additives and surface topographies with the possibility to meet the sharply increasing requirements of performance in combination with a sustainable society. 


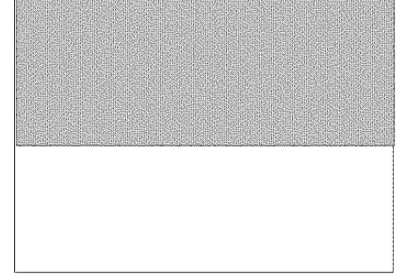

(a)

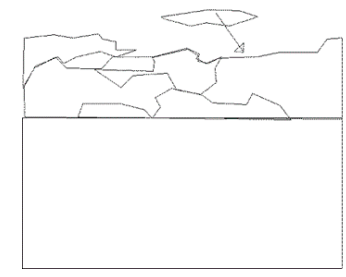

(c)

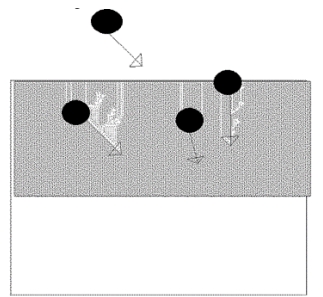

(b)

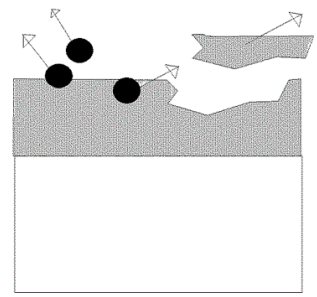

(d)

Figure 21. The four basic categories of tribological surface modification: (a) modification without any material transfer; (b) modification involving material transfer; (c) formation of tribofilm or coating; and (d) wear (loss of particles or atoms from the surface) [58].

\section{Critical Issues Particular to Microforming}

Due to the predominance of surface effects as compared to bulk behavior when dimensions are scaled down, friction and die wear have a considerable impact in microforming, which refers to metal forming processes where at least two dimensions are in the sub-millimeter range [59]. In particular, friction size effects have been studied for microforming and it has been shown in various studies that friction increases when the part size decreases [60-63].

Lubricants are usually used in conventional metal forming processes to avoid excessive friction, which can increase process load, lead to die wear and generate poor product surface finish. However, the use of lubricant in microforming is not economically effective as the surface to volume ratio increases significantly and cleaning becomes an issue when lubricant is trapped in the small features of the die. By evaluating various liquid and solid lubricants Taureza et al. [64] showed that lubricant effectiveness is limited in microforming and can even be reduced for liquid lubricants as explained by the lubricant pocket model [65]. Baek et al. [66] explained that the lubricant ineffectiveness can be related to the fact that the feature size in components produced by microforming is close to the lubricant film thickness, suggesting that the lubricant effectiveness can be retained if the natural lubricant thickness is reduced.

DLC coating was proven to be an efficient way to reduce friction in microforming as shown by the work of Hu et al. [67] using micro deep drawing experiment and Wang et al. [68] in the case of strip drawing. Surface texturing of the die was proposed by Brinksmeier et al. [69] as another mean to control friction in sheet microforming applications and therefore prolong die life. Using a strip drawing test experiment, Brinksmeier et al. [69] have shown that there is an optimum finish for which friction is the lowest and that a smoother surface finish does not necessarily correlate with less friction. Similar applications in the case of bulk forming have been reported by Geiger et al. [70] and Wagner et al. [28] where it was shown that proper surface texturing could increase die life.

In microforming, it was also observed that die life can be affected by galling as shown in experiments by Taureza et al. [64] for aluminum workpiece material where high friction values were explained by the presence of galling marks on the die and workpiece. A similar galling effect was observed by Ghasemali et al. [71] during extrusion of copper micro-pins. Hu et al. [72] studied the wear behavior in micro deep drawing tools. They observed that wear was dominated by adhesive wear on the drawn radius in micro deep drawing of a stainless-steel blank. Increase in friction force 
due to die wear and non-uniform distribution of the wear areas on the drawn radius were highlighted as the mechanism responsible for bottom fracture and cup wall damage, respectively.

\section{Concluding Remarks}

Modeling of tool life has come far, but further work is necessary to fully understand and predict tool life. This is especially true for an increased understanding of the nature of the large variations in tool life found in industry. Tool-life span will be a make or break factor for microforming.

Material properties of tool materials are anisotropic and tool life sensitivity to the anisotropy is depending on both the as-received and in-service conditions. The importance of anisotropy is seemingly increased with increasing tool hardness being a requirement in microforming due to extreme contact pressures.

For fatigue limited tool life, under high stress and low-cycle fatigue conditions, failure due to internal microstructures and inclusions are common. In microforming the requirements on abrasive wear resistance are increased. To improve abrasive wear resistance larger carbides are improve wear resistance but cause negative impact on tooling life as are a common cause of fatigue failures. Furthermore, carbide size influences the attainable surface roughness.

To create the correct combination of base material and coating combined with preconditioning of the tool surface with a residual stress of appropriate level can be used to eliminate the effects from surface particles. The proper preconditioning and choice of optimum coating type and coating thickness for the service conditions of the tooling to manage wear with a minimum impact on fatigue life is a critical skill. For the case of microforming friction management in a non-lubricated condition will also be critical.

Acknowledgments: The authors wish to acknowledge the Singapore Institute of Manufacturing Technology for funding the work under project U09-F-012SU Simulation Tool Failure in Net Shape (Micro) Forming.

Author Contributions: The work was initiated by Anders E. W. Jarfors during his employment with Singapore institute of Manufacturing Technology with support from Atsushi Danno as team member and mentor in a collaborative project with Sylvie J. Castagne and Xinping Zhang. All authors contributed to the writing of the paper but the main bulk of work and finalizing the work was made by Anders E. W. Jarfors and Sylvie J. Castagne.

Conflicts of Interest: The authors declare no conflict of interest. In addition, have conducted an independent study on tool relate issues relevant for microforming. The founding body had no role in the design of the study; nor in the collection, analyses, or interpretation of data; in the writing of the manuscript, and in the decision to publish the results.

\section{References}

1. Del Pozo, D.; de Lacalle, L.N.L.; López, J.M.; Hernández, A.A. Prediction of press/die deformation for an accurate manufacturing of drawing dies. Int. J. Adv. Manuf. Technol. 2008, 37, 649-656. [CrossRef]

2. Knoerr, M.; Lange, K.; Altan, T. Fatigue failure of cold forging tooling: Causes and possible solutions through fatigue analysis. J. Mater. Process. Technol. 1994, 46, 57-71. [CrossRef]

3. Lange, K.; Hettig, A.; Knoerr, M. Increasing tool life in cold forging through advanced design and tool manufacturing techniques. J. Mater. Process. Technol. 1992, 35, 495-513. [CrossRef]

4. GroenBaek, J.; Hensel, C. Advanced Material and Prestress Design of Cold Forging Die. In Proceedings of the 7th ICTP Conference on Advanced Technology of Plasticity, Yokohama, Japan, 28-31 October 2002; pp. 339-350.

5. Meidert, M.; Hansel, H. Net shape cold forging to close tolerances under QS 9000 aspects. J. Mater. Process. Technol. 2000, 98, 150-154. [CrossRef]

6. Tabe, H. Location of crack occurrence in tools. In Proceedings of the Stål 2004, Borlänge, Sweden, 5-6 May 2004.

7. Broeckmann, C. Microstructure and mechanical properties of tool steel. In Proceedings of the 5th International Conference on Tooling, Leoben, Austria, 29 September-1 October 1999; pp. 49-58.

8. Broeckmann, C. Fracture of tool steel on a microscopic scale. In Proceedings of the 4th International Conference on Tooling, Boston, MA, USA, 18-22 November 1996; pp. 491-500. 
9. Li, S. Improve tool life of cold work tools with the use of powder metallurgy tool steels: Understand factors affecting tool life and some common tooling problems. In Proceedings of the 5th International Conference on Tooling, Leoben, Austria, 29 September-1 October 1999.

10. Bohm, H.J.; Eckschlager, A.; Han, W. Modelling phase arrangement effects in high speed tool steels. In Proceedings of the 5th International Conference on Tooling, Leoben, Austria, 29 September-1 October 1999; pp. 147-156.

11. Plankensteiner, A.F.; Rammerstofer, F.G.; Buyachenko, V.A.; Hackl, G. Micro-Meso-Macro-mechanical modelling of the strength behaviour of tool steel. In Proceedings of the 4th International Conference on Tooling, Setubal, Portugal, 25-28 August 2004; pp. 481-490.

12. Falk, B.; Engel, U.; Geiger, M. Estimation of tool life in bulk metal forming based on different failure concepts. J. Mater. Process. Technol. 1998, 80-81, 602-607. [CrossRef]

13. Skov-Hansen, P.; Bay, N.; Gronbaekc, J.; Brondsted, P. Fatigue in cold-forging dies: Tool life analysis. J. Mater. Process. Technol. 1999, 95, 40-48. [CrossRef]

14. Lee, H.C.; Saroosh, M.A.; Song, J.H.; Im, Y.T. The effect of shrink fitting ratios on tool life in bolt forming processes. J. Mater. Process. Technol. 2009, 209, 3766-3775. [CrossRef]

15. Fu, M.W.; Lu, J.; Chan, W.L. Die fatigue life improvement through the rational design of metal-forming system. J. Mater. Process. Technol. 2009, 209, 1074-1084. [CrossRef]

16. Lee, H.C.; Lee, Y.; Lee, S.Y.; Choi, S.; Lee, D.L.; Im, Y.T. Tool life prediction for the bolt forming process based on high-cycle fatigue and wear. J. Mater. Process. Technol. 2008, 201, 348-353. [CrossRef]

17. Wan, W.S.F.S.; Tay, Z.H. Process modelling and simulation of vibratory finishing of fixtured components. In Proceedings of the Euspen International Conference, Delft, The Netherlands, 31 May-4 June 2010.

18. Yokoi, D.; Tsujii, N.; Isomoto, T. Effect of carbide size on mechanical properties of cold work steels. In Proceedings of the 5th International Conference on Tooling, Leoben, Austria, 29 September-1 October 1999.

19. Engel, U. Prediction of tool failure from a probabilistic point of view. J. Mater. Process. Technol. 1994, 42, 1-13. [CrossRef]

20. Sohar, C.R.; Betzwar-Kotas, A.; Gierl, C.; Weiss, B.; Danninger, H. Gigacycle fatigue behavior of a high chromium alloyed cold work tool steel. Int. J. Fatigue 2008, 30, 1137-1149. [CrossRef]

21. Elvira, R.; Gonzalez, L.; de Andoin, A.G.; Molinera, J.; Bertrand, C. Influence of the nature of inclusion population on the low cycle fatigue life of ultra clean high strength steels. In Proceedings of the Stål 2004, Borlänge, Sweden, 5-6 May 2004.

22. Meurling, F.; Melander, A.; Tidesten, M.; Westin, L. Influence of carbide and inclusion contents on the fatigue properties of high speed steels and tool steels. Int. J. Fatigue 2001, 23, 215-224. [CrossRef]

23. Haglund, S. Influence of inclusions in steels during fatigue. In Proceedings of the Stål 2004, Borlänge, Sweden, 5-6 May 2004.

24. Meurling, F. FATSIMR_Fatigue Limit Prediction Software for High Speed Steel and Cold Work Steel Specimens; Report IM-1999-547; Swedish Institute for Metals Research: Stockholm, Sweden.

25. Fredriksson, G.; Bergstrom, J.; Hogmark, S. Fatigure resistance and surface properties of EDMed cold work steels. In Proceedings of the 4th International Conference on Tooling, Boston, MA, USA, 18-22 November 1996; pp. 445-456.

26. Lavender, C.A.; Honga, S.-T.; Smith, M.T.; Johnson, R.T.; Lahrman, D. The effect of laser shock peening on the lifeand failure mode of a cold pilger die. J. Mater. Process. Technol. 2008, 204, 486-491. [CrossRef]

27. Wagner, K.; Putz, A.; Engel, U. Improvement of tool life in cold forging by locally optimized surfaces. J. Mater. Process. Technol. 2006, 177, 206-209. [CrossRef]

28. Wagner, K.; Völkl, R.; Engel, U. Tool life enhancement in cold forging by locally optimized surfaces. J. Mater. Process. Technol. 2008, 201, 2-8. [CrossRef]

29. Bergman, F.; Hedenqvist, P.; Hogmark, S. The influence of primary carbides and test parameters on erosive wear of selected PM high speed steels. Tribol. Int. 1997, 30, 183-191. [CrossRef]

30. Tidesten, M.; Moser, P. Abrasive wear of tool steels; tests versus application studies. In Proceedings of the 4th International Conference on Tooling, Boston, MA, USA, 18-22 November 1996; pp. 83-92.

31. Dohda, K.; Kubota, H.; Tsuchiya, Y.; Taniguchi, Y. Application of hard coatings to ironing dies. In Proceedings of the ICTP Conference on Advanced Technology of Plasticity, Verona, Italy, 9-13 October 2005; p. 329. 
32. Takaishi, K.; Iwaki, T.; Kondo, T.; Sasaki, K.; Abe, Y. Extension of blanking die life by surface coatings. In Proceedings of the 7th ICTP Conference on Advanced Technology of Plasticity, Yokohama, Japan, 28-31 October 2002.

33. Tsuchiya, Y.; Dohda, K.; Kitamura, K. Improvement in anti-flaking properties of DLC-Si coatings and applications to forming die. In Proceedings of the 7th ICTP Conference on Advanced Technology of Plasticity, Gyeongju, Korea, 7-11 September 2008.

34. Takatsuji, N.; Dohda, K.; Makino, T.; Yoshimura, T. Iinfluence of die coating on forming of micro-parts by forward-backward extrusion. In Proceedings of the 9th ICTP Conference on Advanced Technology of Plasticity, Gyeongju, Korea, 7-11 September 2008.

35. Hogmark, S.; Hedenqvist, P. Tribological characterization of thin, hard coatings. Wear 1994, 179, $147-154$. [CrossRef]

36. Hedenqvist, P.; Jacobson, S.; Hogmark, S. Tribological PVD coatings-Characterisation of mechanical properties. Surf. Coat. Technol. 1997, 97, 212-217. [CrossRef]

37. Gahlin, R.; Bromark, M.; Hedenqvist, P.; Hogmark, S.; Hakansson, G. Properties of TiN and CrN coatings deposited at low temperature using reactive arc-evaporation. Surf. Coat. Technol. 1995, 76-77, 174-180.

38. Hollman, P.; Larsson, M.; Hedenqvist, P.; Hogmark, S. Tensile testing as a method for determining the Young's modulus of thin hard coatings. Surf. Coat. Technol. 1997, 90, 234-238. [CrossRef]

39. Wiklund, U.; Gunnars, J.; Hogmark, S. Influence of residual stresses on fracture and delamination of thin hard coatings. Wear 1999, 232, 262-269. [CrossRef]

40. Nordin, M.; Larsson, M.; Hogmark, S. Mechanical and tribological properties of multilayered PVD TiN/CrN. Wear 1999, 232, 221-225. [CrossRef]

41. Bromark, M.; Larsson, M.; Hedenqvist, P.; Hogmark, S. Wear of PVD Ti/TiN multilayer coatings. Surf. Coat. Technol. 1997, 90, 217-223. [CrossRef]

42. Hayakawa, K.; Nakamura, T.; Tanaka, S.; Harada, K. A Testing Method for Estimation of Adhesion Strength of Interface between Forging Tool and Coated Hard Film. In Proceedings of the 7th ICTP Conference on Advanced Technology of Plasticity, Yokohama, Japan, 28-31 October 2002; pp. 799-804.

43. Wang, Z.; Shiraga, H.; Ueda, N.; Matsumoto, T.; Ohhashi, M.; Nakagaki, H. A simple measurement method of compression behavior of cemented carbide for cold forging die. In Proceedings of the 8th ICTP Conference on Advanced Technology of Plasticity, Verona, Italy, 9-13 October 2005.

44. Kubota, H.; Wang, Z.; Tsuchiya, Y.; Taniguchi, Y. Damage behavior of DLC-Si Coating by Vicker's Hardness Test. JSTP 2007, 48, 1017-1021. [CrossRef]

45. Bay, N. The state of the art in cold forging lubrication. J. Mater. Process. Technol. 1994, 46, 19-40. [CrossRef]

46. Hanson, M.; Stavlid, N.; Coronel, E.; Hogmark, S. On adhesion and metal transfer in sliding contact between TiN and austenitic stainless steel. Wear 2008, 264, 781-787. [CrossRef]

47. Berger, M.; Hogmark, S. Tribological properties of selected PVD coatings when slid against ductile materials. Wear 2002, 252, 557-565. [CrossRef]

48. Bromark, M.; Hedenqvist, P.; Hogmark, S. The influence of substrate material on the erosion resistance of TiN coated tool steels. Wear 1995, 186-187, 189-194. [CrossRef]

49. Bromark, M.; Larsson, M.; Hedenqvist, P.; Olsson, M.; Hogmark, S. Influence of substrate surface topography on the critical normal force in scratch adhesion testing of TiN-coated steels. Surf. Coat. Technol. 1992, 52, 195-203. [CrossRef]

50. Podgornik, B.; Hogmark, S.; Sandberg, O. Influence of surface roughness and coating type on the galling properties of coated forming tool steel. Surf. Coat. Technol. 2004, 184, 338-348. [CrossRef]

51. Podgornik, B.; Hogmark, S. Surface modification to improve friction and galling properties of forming tools. J. Mater. Process. Technol. 2006, 174, 334-341. [CrossRef]

52. Popp, U.; Neudecker, T.; Engel, U.; Geiger, M. Excimer laser texturing of hard coated cold forging tools-Investigations on tool life. In Proceedings of the 7th ICTP Conference on Advanced Technology of Plasticity, Yokohama, Japan, 28-31 October 2002; pp. 1638-1699.

53. Kocanda, A. Analysis of LCF behavior of TiN coated tool steel for cold forging. In Proceedings of the 7th ICTP Conference on Advanced Technology of Plasticity, Yokohama, Japan, 28-31 October 2002; pp. 793-798.

54. Wang, Z.; Nakashima, I.; Ohhashi, M.; Matsumoto, T. Fatigue crack growth behaviour of cemented carbide die in cold forging process. In Proceedings of the 8th ICTP Conference on Advanced Technology of Plasticity, Verona, Italy, 9-13 October 2005. 
55. Baragetti, S.; Tordini, F. Fatigue resistance of PECVD coated steel alloy. Int. J. Fatigue 2007, 29, $1832-1838$. [CrossRef]

56. Gåård, A.; Krakhmalev, P.; Bergstrom, J. Wear Mechanisms in Galling: Cold Work Tool Materials Sliding against High-strength Carbon Steel Sheets. Tribol. Lett. 2009, 33, 45-53. [CrossRef]

57. Bryggman, U.; Hogmark, S.; Vingsbo, O. Prediction of gouging abrasion resistance of steel by pendulum grooving and other laboratory test methods. Wear 1987, 115, 203-213. [CrossRef]

58. Jacobson, S.; Hogmark, S. Surface modifications in tribological contacts. Wear 2009, 266, 370-376. [CrossRef]

59. Geiger, M.; Kleiner, M.; Eckstein, R.; Tiesler, N.; Engel, U. Microforming. CIRP Ann. Manuf. Technol. 2001, 50, 445-462. [CrossRef]

60. Geiger, M.; Engel, U.; Pfestorf, M. New developments for the qualification of technical surfaces in forming processes. CIRP Ann. Manuf. Technol. 1997, 46, 77-80. [CrossRef]

61. Engel, U.; Messner, A.; Tiesler, N. Cold forging of microparts-Effects of miniaturization on friction. In Proceedings of the 1st ESAFORM Conference on Materials Forming, Sophia Antipolis, France, 1998; pp. 77-80.

62. Engel, U. Tribology in microforming. Wear 2006, 260, 265-273. [CrossRef]

63. Guo, B.; Gong, F.; Wang, C.; Shan, D. Flow stress and tribology size effects in scaled down cylinder compression. Trans. Nonferrous Met. Soc. China 2009, 19, s516-s520. [CrossRef]

64. Taureza, M.; Song, X.; Castagne, S. On the influence of workpiece material on friction in microforming and lubricant effectiveness. J. Mater. Process. Technol. 2014, 214, 998-1007. [CrossRef]

65. Peng, L.; Lai, X.; Lee, H.J.; Song, J.H.; Ni, J. Friction behavior modeling and analysis in micro/meso scale metal forming process. Mater. Des. 2010, 31, 1953-1961. [CrossRef]

66. Baek, S.W.; Oh, S.I.; Rhim, S.H. Lubrication for micro forming of ultra thin metal foil. CIRP Ann. Manuf. Technol. 2006, 55, 295-298. [CrossRef]

67. Hu, Z.; Schubnov, A.; Vollertsen, F. Tribological behaviour of DLC-films and their application in micro deep drawing. J. Mater. Process. Technol. 2012, 212, 647-652. [CrossRef]

68. Wang, C.; Guo, B.; Shan, D.; Bai, X. Tribological behaviors of DLC film deposited on female die used in strip drawing. J. Mater. Process. Technol. 2013, 213, 323-329. [CrossRef]

69. Brinksmeier, E.; Riemer, O.; Twardy, S. Tribological behavior of micro structured surfaces for micro forming tools. Int. J. Mach. Tools Manuf. 2010, 50, 425-430. [CrossRef]

70. Geiger, M.; Popp, U.; Engel, U. Excimer laser micro texturing of cold forging tool surfaces-Influence on tool life. CIRP Ann. Manuf. Technol. 2002, 51, 231-234. [CrossRef]

71. Ghassemali, E.; Tan, M.-J.; Jarfors, A.E.W.; Lim, S.C.V. Progressive microforming process: Towards the mass production of micro-parts using sheet metal. Int. J. Adv. Manuf. Technol. 2013, 66, 611-621. [CrossRef]

72. Hu, Z.; Luepke, S.H.; von Kopylow, C.; Vollertsen, F. No Characteristic of wear behavior of micro deep drawing tools. In Proceedings of the AIP Conference, Paris, France, 24-27 October 2010; pp. 335-340.

(C) 2016 by the authors; licensee MDPI, Basel, Switzerland. This article is an open access article distributed under the terms and conditions of the Creative Commons Attribution (CC-BY) license (http://creativecommons.org/licenses/by/4.0/). 